\title{
Tropopause Folding Events to the East of Tibetan Plateau in Boreal Summer and their Remote Relation to the Circulation Anomalies over Northeastern Atlantic
}

\section{Chuandong Zhu ( $\sim$ zcd@lasg.iap.ac.cn )}

Institute of Atmospheric Physics Chinese Academy of Sciences https://orcid.org/0000-0002-83029444

\section{Rongcai Ren}

Institute of Atmospheric Physics Chinese Academy of Sciences

\section{Research Article}

Keywords: Tropopause folding to the east of Tibetan Plateau, Circulation and weather, South Asian high, Rossby wave train

Posted Date: May 10th, 2021

DOl: https://doi.org/10.21203/rs.3.rs-231772/v1

License: (c) (1) This work is licensed under a Creative Commons Attribution 4.0 International License.

Read Full License 

summer and their remote relation to the circulation anomalies over

$5 \quad{ }^{1}$ State Key Laboratory of Numerical Modeling for Atmospheric Sciences and 6 Geophysical Fluid Dynamics, Institute of Atmospheric Physics, Chinese Academy of $7 \quad$ Sciences, Beijing 100029, China

$8{ }^{2}$ Collaborative Innovation Center on Forecast and Evaluation of Meteorological 9 Disasters and KLME, Nanjing University of Information Science and Technology,

$10 \quad$ Nanjing 210044, China

$11{ }^{3}$ Hubei Meteorological Service Center, Wuhan 430205, China 


\section{Abstract}

This study investigates the occurrence of tropopause folding (TF) events to the east of Tibetan Plateau (ETP) (TF-ETP) in boreal summer. Firstly, it is revealed that, anomalously frequent TF-ETP occurrence in summer, always corresponds to a significant dipole rainfall anomaly pattern over China, with negative rainfall anomalies over the upper and middle reaches of the Yangtze and Yellow river valleys, and positive rainfall anomalies over eastern China. Secondly, the South Asian High (SAH) center over Tibetan Plateau (TP) is found to be anomalously stronger when occurrence of TF-ETP events is frequent. Further diagnosis indicates that, the TF-ETP occurrence is related to an eastward propagating Rossby wave train (RWT) that originates from a barotropic low anomaly center over the northeastern Atlantic (NEA) about one-week before. The RWT propagates downstream via Western Europe, the west of Baikal and down to East Asia along the mid-latitude westerlies, and is connected to a high anomaly center over the north rim of TP, which enhances the SAH center over TP. The enhanced SAH in turn favors the southward and downward PV intrusion and the subsequent occurrence of TF-ETP. Furthermore, the low anomaly center that initiates the RWT is related to dynamical forcing of transient eddy activity over the NEA, which induces the low via eddy-forced upper divergence and its pumping. Finally, such local and remote processes are confirmed in a typical TF-ETP case. The ERA-Interim daily fields during 1979-2018 is used.

Key words: Tropopause folding to the east of Tibetan Plateau, Circulation and weather, South Asian high, Rossby wave train. 


\section{Introduction}

Tropopause folding (TF), or drastic deformation of the tropopause, is one of the important stratosphere-troposphere interaction processes, and has been known to be crucial for regional circulation and weather anomalies in the troposphere (Hoskins et al. 1985; Holton et al. 1995; Tyrlis et al. 2013, 2014; Škerlak et al. 2014, 2015; Akritidis et al. 2016, 2019; Vaughan et al. 2017; Dafka et al. 2020). TF was first recognized in 1930s, when multiple stable stratification of temperature was detected in the vertical direction from radio soundings. A conceptual TF model was then put forward to explain such observational phenomenon and to understand the dynamical mechanisms behind (Bjerknes and Palmén 1937). Because of the sharp increase in potential vorticity (PV) from the troposphere to stratosphere, the tropopause in the extratropics can also be represented by the 2 PVU surface $\left(1\right.$ PVU $=10^{-6} \mathrm{~m}^{2} \mathrm{~s}^{-1} \mathrm{~K}$ $\mathrm{kg}^{-1}$ ) (Ertel 1942; Reed 1955; Hoskins et al. 1985; Holton et al. 1995). Based on this, TF events were also defined when multiple tropopause (i.e., the dynamical 2 PVU surface) are detected in the vertical direction (Sprenger et al. 2003), which mostly manifests a downward PV intrusion from the stratosphere (e.g., Hoskins et al. 1985). $\mathrm{TF}$ events can be classified into three types based on the vertical span of them: namely the vertically shallow, the medium and the deep ones (Sprenger et al. 2003).

When a TF event occurs, the downward intrusion of high PV air from the stratosphere can result in significantly upper-level positive PV anomalies (e.g., Hoskins et al. 1985; Tyrlis et al. 2013; Akritidis et al. 2016). The upper-level positive PV perturbations can induce upward/downward air motion in the middle and lower troposphere 
downstream/upstream of the perturbations (Hoskins et al. 1985, 2003), and thus promote the development of deep convection due to the reduced static stability beneath the positive PV perturbations (Morcrette et al. 2007; Russell et al. 2012). In addition, interactions between such upper-level PV perturbations and the circulation in the lower troposphere may also lead to rapid cyclogenesis in the lower troposphere (e.g., Uccellini 1990; Browning and Golding 1995; Wernli et al. 2002), which is usually accompanied with surface wind gust, extreme precipitation and other severe weather anomalies in the lower troposphere (e.g., Goering et al. 2001; Antonescu et al. 2013; Kim et al. 2013; Škerlak et al. 2015). Nevertheless, intensity of the TF-related circulation and weather anomalies are largely associated with the vertical span of the TFs. Vertically deep and moderately deep TFs usually result in surface wind gust and rainfall extremes, while vertically shallow TFs can induce relatively weaker rainfall

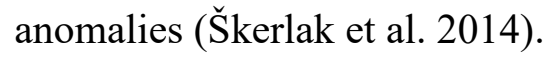

Most deep TFs, though being much less frequent $(<0.1 \%)$ than shallow TFs (up to $15 \%$ ), occur mostly in winter because of the much stronger upper tropospheric frontogenesis along the subtropical westerly jet (SWJ) located around $30^{\circ} \mathrm{N}$ (Škerlak et al. 2015). They are often observed in the region from North America continent to North Atlantic along the SWJ over there (Elbern et al. 1998; Sprenger et al. 2003; Schmidt et al. 2006; Škerlak et al. 2015). Other TFs in winter, especially those often observed in a zonally elongated region from the southeastern edge of Tibetan Plateau (TP) to the south of Japan, are mostly shallow (Sprenger et al. 2003; Škerlak et al. 2015). In summer, vertically deep TFs are rarely observed due to the relatively much 
weaker frontogenesis along the much weaker SWJ. The TFs frequently occurring along the SWJ across the Eurasian continent are also mainly shallow (Tyrlis et al. 2014; ŠSkerlak et al. 2015). Based on the summertime climatology of the TF frequency, two hot spots are identified respectively over the eastern Mediterranean region and over the central Asian region (Sprenger et al. 2003; Sprenger et al. 2003; Tyrlis et al. 2014; Škerlak et al. 2014, 2015), which coincide with two entrance regions of the SWJ core centers (Sawyer 1956; Elbern et al. 1998; Sorensen and Nielsen 2001). They were also related to dynamical interactions between the SAH and the SWJ (Traub and Lelieveld 2003). At the western flank of the SAH, convergent southerlies prevail in the upper troposphere over the eastern Mediterranean and central Asian regions, which help to accelerate the SWJ and enhance the local vertical wind shear, thus favoring the formation of a jet streak and TF occurrence there (Traub and Lelieveld 2003). In agreement with this, recent studies indicated a possible linkage between the TFs over these two hot spots with the Asian summer monsoon (Tyrlis et al. 2014; Wu et al. 2018). It was found that TFs tend to occur at the northwestern side of the monsoon-related upper-level anticyclone (i.e., the SAH), and become more frequent when the monsoon SAH intensifies (Tyrlis et al. 2014; Wu et al. 2018).

On average, TP is a negative PV source for the upper atmosphere because of its powerful thermal forcing in summer, which is highly responsible for the existence of the giant SAH system (Wu and Liu 2000; Liu et al. 2001). In pace with the variation of TP thermal forcing, the intensity as well as the zonal location of the SAH center oscillates eastward and westward periodically in seasonal and sub-seasonal timescale 
(Ren et al. 2015; Yang and Li 2016; Ren et al. 2019). Diagnosis of the total PV fields during SAH oscillations demonstrated that the zonal oscillation of the SAH center is accompanied by periodic southward and westward eddy shedding around the eastern and southeastern edge of the SAH (Hsu and Plumb 2000; Popovic and Plumb 2001; Liu et al. 2007; Vogel et al. 2014; Ortega et al. 2017). Particularly, the southward eddy shedding can result in filament-like high PV center to the east of SAH (Vogel et al. 2014; Ortega et al. 2017). Meanwhile, the powerful TP thermal forcing also results in a radical downward concave of isentropic surfaces, but a radical uplift of PV surfaces as well as the tropopause over TP. The isentropic surfaces and PV surfaces (or the tropopause) may intersect almost orthogonally over the surrounding region of TP (Ren et al. 2014; Xia et al. 2016). This gives rise to southward and downward high PV intrusion along isentropic surfaces from the extratropical stratosphere into the lower latitude troposphere over the ETP region (Ren et al. 2014; Xia et al. 2016), and thus favors the TF-ETP occurrence there in summer. Tyrlis et al. (2013) also suggested that upper-level northerlies and accompanied subsidence are favorable large-scale conditions for the occurrence of TF-ETP.

The occurrence of TF-ETP, though much less frequent than the TFs over the two hot spots (Tyrlis et al. 2013, 2014; Škerlak et al. 2014, 2015), is closely related with the circulation and weather anomalies over East Asia and China. Previous studies indicated that the high PV air near the tropopause can penetrate into the troposphere during TF-ETP events in summer, favoring the development of strong convection and heavy precipitation over East Asia (Liu and Li 2010; Shou et al. 2014; Cui et al. 2016; 
Zhao and Yao 2017). However, most of the evidence of TF-ETP occurrence and its impacts are mostly based on scatted case studies. With the much-extended time series of related meteorological data fields, a more comprehensive investigation is still lack, which has obviously hindered our further understanding of the thermodynamic processes related to TF-ETP occurrence and its general climate impacts. By using the currently available longer time series provided by ERA-Interim, this study is aimed to perform a more comprehensive investigation on TP-ETP events and provide a much general picture of the impacts of TF-ETP occurrence on the tropospheric circulation and weather anomalies over East Asia and China in summer. We will also explore the relationship between the SAH and TF-ETP occurrence and the dynamical processes linking the TF-ETP and the SAH. The results may advance our understanding of the weather and climate anomalies in East Asia and China from a new perspective and benefit the predictions of them.

This paper is organized as follows. Section 2 introduces the data and method; Section 3 shows the occurrence of TF-ETP and its impacts on the surrounding circulation and rainfall, demonstrates the association of TF-ETP occurrence with SAH variability, and provides evidence of a remote linkage from TF-ETP to circulation anomalies over the northeastern Atlantic (NEA) by the results of composite and regressed analysis; Section 4 presents a typical TF-ETP case to verify the displayed processes in section 3; Summary is provided in Section 5.

\section{Data and Method}



European Center for Medium-Range Weather Forecasts (Dee et al. 2011) are used, which cover the period 1979-2018, with a horizontal resolution of $1.5^{\circ} \times 1.5^{\circ}$ in latitude and longitude and on 37 pressure levels spanning from $1000-\mathrm{hPa}$ to $1-\mathrm{hPa}$ in the vertical direction. To diagnose TF events using isentropic circulation fields, we do interpolation of circulation fields from the 37 isobaric surfaces onto 17 isentropic surfaces spanning from $260 \mathrm{~K}$ to $420 \mathrm{~K}$. The daily precipitation data on a horizontal

\subsection{Method}

The 2 PVU surface (1PVU $=10^{-6} \mathrm{~m}^{2} \mathrm{~s}^{-1} \mathrm{~K} \mathrm{~kg}^{-1}$ ) is widely used to represent the dynamical tropopause (e.g., Hoskins et al. 1985; Holton et al. 1995). A TF is usually defined at one grid point when multiple dynamical tropopause (2 PVU surface) can be found in the vertical direction (Sprenger et al. 2003; Škerlak et al. 2014). Specifically, with the occurrence of a TF at one grid point, three pressure surfaces (upper one: $P_{U}$; middle one: $P_{M}$; lower one: $P_{L}$ ) that intersect with the tropopause can be detected. The pressure difference between the middle and upper $\left(\Delta p=P_{M}-P_{U}\right)$ is regarded as the vertical extent of the TF. And TFs with $\Delta p \geq 350-\mathrm{hPa}$ are defined as deep TFs, those 
with $200 \leq \Delta p<350-\mathrm{hPa}$ are defined as medium TFs, and those with $50 \leq \Delta p<$ 200-hPa are defined as shallow TFs, while those with $\Delta p<50-\mathrm{hPa}$ are not considered as TFs (Škerlak et al. 2014). As vast majority of TFs in summer are vertically shallow (Tyrlis et al. 2014; Škerlak et al. 2014, 2015), the TFs concerned in this study are all shallow TFs.

Firstly, we calculate the TF frequency at each grid point based on the daily binary ( 0 : no folding; 1 : folding) time series in the 40 summer seasons (July-August) from 1979 to 2018:

$$
f_{T F}(x, y)=\frac{\sum_{t=1}^{t=N} T F(t, x, y)}{N},
$$

where

$$
\mathrm{TF}(t, \mathrm{x}, y)=\left\{\begin{array}{ll}
0, & \text { no folding } \\
1, & \text { folding }
\end{array},\right.
$$

$(x, y)$ represents the horizontal position of the grid point, $t$ is time, $N$ is the sample size of the selected time series. Secondly, we define a TF-ETP index (TFI) by averaging the above-mentioned daily binary time series $(T F(\mathrm{t}, \mathrm{x}, \mathrm{y}))$ over the area to the east of $\mathrm{TP}$, to measure the TF occurrence over the area to the ETP region $\left(33^{\circ}-45^{\circ} \mathrm{N}\right.$, $105^{\circ}-117^{\circ} \mathrm{E}$; red dash box in Fig. 1a) quantitatively. Subsequently, 438 cases of high TFI (i.e., TF-ETP is frequent) are identified with a threshold of 1 standard deviation of the TFI time series (shown in Fig. 1b). Moreover, a PV index (PVI) manifesting the downward intrusion of stratospheric PV is also defined by averaging the $300-\mathrm{hPa} \mathrm{PV}$ anomalies over the same area. The TFI as well as the PVI is used for the following investigation of TF-ETP. 


$$
\mathrm{F}_{s}=\frac{p \cos \phi}{p_{0}} \times\left(\begin{array}{c}
v^{\prime 2}-\frac{1}{2 \Omega a \sin 2 \phi} \frac{\partial\left(v^{\prime} \Phi^{\prime}\right)}{\partial \lambda} \\
-v^{\prime} u^{\prime}+\frac{1}{2 \Omega a \sin 2 \phi} \frac{\partial\left(u^{\prime} \Phi^{\prime}\right)}{\partial \lambda} \\
\frac{2 \Omega \sin \phi}{S}\left[v^{\prime} T^{\prime}-\frac{1}{2 \Omega a \sin 2 \phi} \frac{\partial\left(T^{\prime} \Phi^{\prime}\right)}{\partial \lambda}\right]
\end{array}\right),
$$

194 where

$$
\mathrm{S}=\frac{\partial \hat{T}}{\partial z}+H
$$

196 denotes the static stability (the caret means area-average over the region to the north 197 of $\left.20^{\circ} \mathrm{N}\right), \varphi$ and $\lambda$ are latitude and longitude, $u$ and $v$ denote zonal wind and meridional wind, $\Phi$ refers to the geopotential height, $T$ refers to the air temperature, $a$ is Earth's radius, and $\Omega$ is Earth's rotational angular velocity. The prime represents deviation from zonal mean. As wave activity flux is parallel to the local group velocity of a Rossby wave, it can be used to denote the propagating direction of Rossby wave energy. To diagnose transient eddy activities associated with the

203 development of RWT, we first extract synoptic-scale (2.5-6 days) transient eddy component $\left(u^{\prime}, v^{\prime}\right)$ from the daily horizontal wind field using Lanczos band pass filter (Duchon 1979). We then calculate the transient eddy kinetic energy $206\left(u^{\prime 2}+v^{\prime 2}\right) / 2$ in the upper troposphere at $300-\mathrm{hPa}$.

\section{Results from composite and regression}



the SWJ and the SAH at 200-hPa in Fig. 1a. It is seen that TFs do mainly occur along

211 the SWJ that lies to the north edge of the SAH, and two major TF frequency centers 212 (up to $10 \%$ and $8 \%$ ) are found respectively over the eastern Mediterranean and over 213 the central Asia region (Fig. 1a), as also indicated in previous studies (Tyrlis et al. 214 2014; Škerlak et al. 2015). These two centers are just at the upstream of two SWJ core 215 centers because of much stronger upper-level frontogenesis in the entrance region of 216 SWJ (Elbern et al. 1998; Sorensen and Nielsen 2001). It can also be seen from Fig. 1a 217 that, there exists a minor TF frequency center (up to 3\%) over the east of TP, which 218 we will mainly concern because of the critical impacts of its variability on 219 tropospheric circulation and weather in East Asia and China, as will be shown in Fig. variation of TF-ETP, which exhibits considerably strong pulse-like variability the above definition, every TFI pulse basically indicates that TFs are occurring over a considerable large area to the east of TP. Power spectral analysis of the daily TFI reveals that the pulse-like variability in summer is dominated by a quasi-biweekly period (about 13 days) (Fig. 1c). This implies that TF-ETP is indeed an atmospheric phenomenon that occurs within the Asian summer monsoon system where quasi-biweekly variability is recurrent during its mature phase (Krishnamurti and Bhalme 1976; Krishnamurti and Ardanuy 1980; Ortega et al. 2017).

Taking unit standard deviation of the daily TFI time series as a threshold, Figs. 
2a-b show vertical cross-sections of the composite PV and its anomalies along $39^{\circ} \mathrm{N}$ and along $111^{\circ} \mathrm{E}$, respectively. It is clear that summer climatology of 2 PVU surface to the east of TP (i.e., the dynamical tropopause) is remarkably concave, manifesting the effect of frequent TF occurrence there. As occurrence of TFs is accompanied with downward and southward high PV intrusion from the stratosphere into the tropospheric layer, significant positive PV anomalies can be induced in the upper troposphere. From the PV perspective put forward by Hoskins et al. (1985, 2003), motion ahead, which can act to suppress and promote the local convective activities respectively. As a result, cyclogenesis will be favored ahead of upper-level positive divergence anomalies accompanied with negative rainfall anomalies appear in the 
the anomalous northerlies prevailing behind the cyclonic anomaly center (Figs. 3b-c). In general, frequent TF-ETP occurrence is related to a significant dipole rainfall anomaly pattern over China, with negative rainfall anomalies in the upper and middle reaches of the Yangtze and Yellow river valleys, and positive rainfall anomalies in Eastern China.

\subsection{TF-ETP occurrence and SAH variability}

Figure 4 shows the composite distributions of TF frequency, the SAH and the related SWJ at 200-hPa for high TFI days. As anticipated from the TFI definition, the maximal frequency of TFs over the ETP region during high TFI days can be as high as $10 \%$, which is accompanied by an anomalously stronger SAH center over the TP region compared with the summer climatology (Fig. 4 vs Fig. 1a). This suggests that frequent TF activity over the east of TP is closely related to an anomalously stronger SAH center over TP. The much stronger northerlies to the northeast of a stronger SAH center may act to enhance the downward and southward PV intrusion that induces TF activities (as will be shown in Fig. 5a). In addition, the TF activity over the north of TP during high TFI days is also much active than that in the summer climatology, which can be attributed to the stronger SWJ to the north of a relatively stronger SAH center (Fig. 4 vs Fig. 1a). It should be noted that, the close relationship between the TF-ETP occurrence and the SAH intensity over TP does not indicate a direct relation between the TF-ETP occurrence and the quasi-biweekly east-west oscillation of the SAH center. In fact, the correlation between the TF-ETP occurrence and the quasi-biweekly east-west oscillation of the SAH center is just moderate and 
statistically insignificant (not shown). This implies that the east-west oscillation of the SAH center may not fully represent the intensity variation of the SAH over TP.

\subsection{A Rossby wave train (RWT) linking the TF-ETP occurrence to the NEA}

Shown in Fig. 5a are the composite meridional wind and vertical motion anomalies at $200-\mathrm{hPa}$ for high TFI days. Firstly, the significant northerly anomaly center to the northeast of TP (Fig. 5a) is obviously related to an anomalously stronger SAH center over TP (Fig. 5b). Associated with this are significant descent anomalies to the northeast of TP (Fig. 5a), which may be a manifestation of the enhanced TF-related downward and southward PV intrusion from the extratropical stratosphere. Observing the successive positive and negative meridional wind anomaly centers across Eurasian continent, a clear RWT pattern can be identified, which passes across Western Europe, the western Russia, the northwest of Baikal, and the northeast of TP and down to the east of Hetao Plain (Fig. 5a). Similar RWT pattern can be seen from the composite geopotential height anomalies at $200-\mathrm{hPa}$, which is consisted of three high anomaly centers respectively over Western Europe, the north rim of TP and the Sea of Japan; and two low anomaly centers over the west of Baikal and the northeast of TP (Fig. 5b). Existence of the RWT is confirmed by the composite wave activity flux anomalies (Fig. 5b). It is seen that the RWT originates from Western Europe, then propagates eastward along the north edge of the SWJ, and happens to shift southeastward when it goes across the strongest core of the SWJ that is just to the north of the SAH center (Fig. 5b) because of the Rossby wave-guide effect of the SWJ (Hoskins and Ambrizzi 1993; Terao 1999). 
high TFI days, can help to intensify the SAH (Fig. 5b). The intensified SAH can in turn, lead to anomalously strong northerlies, and thus descent anomalies over the northeast of TP as shown in Fig. 5a, favoring the occurrence of TF-ETP. These results suggest that the occurrence of TF-ETP may be remotely connected to the circulation anomalies over Western Europe via this upper-level RWT. anomalous low over the northeast of Mediterranean and an anomalous high over 318 Caspian Sea (Fig. 6a). The wave activity flux anomalies indicate a RWT pattern

As suggested by previous studies, TF activity is usually accompanied by significant downward PV intrusion from the lower stratosphere to the upper troposphere (e.g., Hoskins et al. 1985; Tyrlis et al. 2013; Akritidis et al. 2016). TF-ETP events also correspond well to significant PV anomalies around $300-\mathrm{hPa}$ over the ETP region as shown in Fig. 3a. Next, we define a PV index (PVI) by averaging the $\mathrm{PV}$ anomalies at $300-\mathrm{hPa}$ over the ETP region, to obtain a much smoother temporal evolution of the TF-ETP activities compared to the TFI. The PVI is used below to further investigate the origin and evolution of the above-mentioned RWT.

Figure 6 shows the lead/lag regressions of geopotential height, horizontal wave activity flux anomalies, and vertical motion anomalies at 200-hPa against the PVI in boreal summer. At day -7 (i.e., seven days before TF-ETP occurrence), an anomalous low over the NEA begins to act as a source of Rossby wave. And a RWT is initiated, propagating downstream, resulting in an anomalous high over Western Europe, an connecting these anomaly centers. 
westerlies in the mid-latitudes, the three downstream anomaly centers along the RWT, get intensified successively. Meanwhile, the initial low anomaly center over the NEA region begins to get gradually weakened (Figs. 6a-d). During this period, the anomaly centers also move eastward along the RWT. Till day -3 , the RWT has propagated further eastward along the SWJ to the east of TP as suggested by wave activity flux anomalies (Fig. 6e). Correspondingly, new anomaly centers appear farther relatively strong high anomaly center over the east of TP (Fig. 6e). Subsequently, the RWT continues to propagate eastward, with gradual intensification and eastward movement of those anomaly centers (except the high anomaly center over Western Europe) (Figs. $6 \mathrm{f}-\mathrm{h}$ ). The low anomaly center from the NEA region, however, gradually diminishes and nearly disappears till day -2 (Figs. 6e-f). Then a complete RWT is consisted of three high anomaly centers respectively over Western Europe, the north rim of TP and the Sea of Japan, and two low anomaly centers over the region west of Baikal and northeast of TP (Fig. 6h). Accompanying the development of the RWT, significant descent/ascent anomalies also become significant ahead of the high/low anomaly centers along the RWT, especially the descent anomaly center ahead of the high anomaly center over the northwestern TP (Fig. 6e). This descent anomaly center is getting remarkably intensified while moving eastward (Figs. $6 \mathrm{f}-\mathrm{h}$ ). It becomes the strongest when it arrives in the region to the northeast of TP (also the northeast of the SAH) till day 0, which favors the occurrence of TF-ETP there (Fig. 
6h). It should be noted that the RWT over Eurasian continent at day 0 highly resembles that of the composite result against the TFI (Fig. 6h vs. Fig. 5b), confirming again the robustness of the TF-ETP-related RWT as well as the reasonableness of our choice to use the PVI to investigate the origin and evolution of the RWT.

To further demonstrate the occurrence of PV intrusion associated with TF-ETP, we show in Fig. 7 the lead/lag regressions of PV, meridional PV advection (MPVA) and meridional wind anomalies at $200-\mathrm{hPa}$ against the PVI. Obviously, the RWT pattern manifested by PV anomalies resembles that in Figs. 5-6. It extends from the NEA to Caspian Sea region at day -7 , consisted of two positive PV anomaly centers respectively over the NEA and the north of Mediterranean, and two negative PV anomaly centers respectively over Western Europe and Caspian Sea region (Fig. 7a). From day -7 to day -4 , while most of the downstream PV anomaly centers gradually get intensified accompanying the eastward propagation of the RWT, the positive PV anomaly center originally located over the NEA gradually get weakened (Figs. 7a-d).

When the RWT propagates downstream to the north of TP till day -4 , a positive PV anomaly center appears over there (Fig. 7d). Later, with the decaying of the initiated positive PV anomaly over the NEA, the RWT pattern is clear over the region from Western Europe to East China at day -2 (Fig. 7f). Till day 0 when TF-ETP occurs, the RWT has propagated downstream to the Sea of Japan, with remarkably intensified positive PV anomalies respectively over the west of Baikal and northeast of TP and negative PV anomalies respectively over the north rim of TP and the Sea of Japan (Fig. 7h). It should be noted that, ahead of the negative PV anomaly center over the 
north rim of TP, there do exist significant northerly and positive MPVA anomalies, which favor the occurrence of TF-ETP (Fig. 7h).

\subsection{Origin of the low anomaly center over the NEA}

We know from above that, the TF-ETP-related RWT is initiated from a low anomaly center over the NEA (i.e., the northeastern Atlantic). In this section, we further investigate the possible origin of this low anomaly center over the NEA. Previous studies indicated that the North Atlantic, located at the exit region of the North American SWJ, is one of the most active regions with synoptic-scale transient eddy activities which can excite low-frequency circulation anomalies (Blackmon, 1976; Holopainen et al. 1982) and are maintained by recurrent barotropic energy conversion from the background flow (Xu et al. 2019). We show in Fig. 8a the lead regressions of transient eddy kinetic energy anomalies at 300-hPa against the PVI. Since day -9 before TF-ETP occurrence, there appear positive anomalies of transient eddy kinetic energy over the NEA, which are gradually enhanced and become the strongest at day -7 , indicating anomalously stronger transient eddy activities over the NEA before the TF-ETP occurrence. It is also seen from Fig. 8a that the anomalously stronger transient eddy activities are accompanied by positive vorticity advection anomalies over the NEA, which manifest the dynamical effect of anomalously stronger transient eddy activities. Previous studies also suggested that synoptic-scale transient eddy activities can lead to low-frequency circulation anomalies by inducing eddy vorticity (Lau and Holopainen, 1984; Mullen, 1987; Lau and Nath,1991). Fig. $8 \mathrm{~b}$ shows the spatial pattern of the transient eddy kinetic energy and vorticity 
advection anomalies at day -7 , and location of the westerly jet in boreal summer. It is seen that active transient eddy activities are located at the right side of the exit region of the North American SWJ, accompanied by a vorticity advection anomaly center.

To further demonstrate the dynamical processes via which the NEA low anomaly center is excited, we display in Figs. $9 \mathrm{a}-\mathrm{b}$ the vertical cross-sections of the regressed circulation anomalies over the NEA at day -7 . It is seen that, associated with the anomalously strong transient eddy forcing and positive vorticity advection, there exist low-frequency divergence anomalies over the NEA in the upper troposphere, which are synchronized with dynamical ascent and convergence anomalies in the lower troposphere due to the dynamical pumping effect of the upper divergence. The lower convergence anomalies in turn are related with positive vorticity (or cyclonic) anomalies in the lower troposphere. This explains the vertically barotropic structure of the low anomaly center over the NEA (Fig. 9a). The dynamical nature of this low anomaly center can also be seen clearly from the same barotropic structure of geopotential height anomalies, which is corresponded with cold anomalies in the troposphere below $250-\mathrm{hPa}$ due to the adiabatic cooling caused by the dynamical ascent anomalies (Fig. 9b). Therefore, it is the dynamical forcing of the anomalously stronger transient eddy activities that has excited the NEA low anomaly center that initiates the RWT propagating downstream to East Asia. Consistent with this, previous studies also showed that cyclone activities are indeed active over the North Atlantic stretching from the east coast of America to the west coast of Western Europe (Sanders et al. 1980; Allen et al. 2010), and those originated in the eastern North 
Atlantic are characterized with barotropic structure (Lau, 1979; Hoskins and Valdes, 1990).

To summarize, the TF-ETP occurrence, though relatively less frequent than the two hot-spots of TFs respectively over the eastern Mediterranean region and over the central Asian region, has significant impacts on the rainfall anomaly pattern over East Asia; It is remotely connected to the transient eddy forcing anomalies over the NEA region via a RWT that successively propagates eastward to East Asia. The RWT connects to a high anomaly center over the north rim of TP, which helps to enhance the SAH center over TP. The enhanced SAH center can then induce anomalously stronger northerlies and subsidence motion, and consequently contribute to stronger southward and downward PV intrusion over the northeast of TP, which favors the occurrence of TF-ETP.

\section{A typical TF-ETP case in 1990}

To verify the composite and regressed results in the above section, next we choose a typical TF-ETP event occurred on 3 August 1990. Firstly, it is seen from Fig. 10a that, there exist strong PV anomalies in the upper troposphere over the ETP region associated with the strong southward and downward PV intrusion during this TF-ETP event (Figs. 11a-b). In association with this, large amount of rainfall can be observed in Eastern China and less amount of rainfall in the upper and middle reaches of the Yangtze and Yellow river valleys (Fig. 10b). Particularly, it can be seen that this anomalous dipole pattern of rainfall over China is related to the strong descent-ascent anomaly pattern in the mid-troposphere from the descent region 
behind, to the ascent region ahead of the PV anomaly center in the upper layer (Figs. 11c-d).

In Figure 12, we display the synchronized evolution of the tropopause and its folding locations, the SAH at $200-\mathrm{hPa}$, and the $\mathrm{PV}$ and meridional wind anomalies at 350K isentropic surface. On 26 July, positive PV anomalies appear over the NEA (Fig. 12a), resembling to the regressed results shown in Fig. 7a. Southeastward downstream are negative, positive, and negative PV anomalies prevailing respectively over the west coast of Western Europe, the Western Europe, and the region from eastern Mediterranean to the northwest of TP. This corresponds to a SAH center over Iranian Plateau (Fig. 12a). With the eastward movement and intensification of the negative PV anomalies along the SWJ north of the SAH from 26 to 30 July, the SAH center shifts eastward toward TP and gets intensified, corresponding to simultaneously eastward moving and strengthening of the northerly anomalies over the northeast of the SAH center (Figs. 12a-c). The strengthened northerlies are followed by southward high PV intrusion downstream of the SAH center, as manifested by the southward deformation of the tropopause as well as the consequent positive PV anomalies north of TP (Fig. 12c). On 1 August, accompanying the eastward movement of negative PV anomalies over the north of TP, the SAH center has shifted to the western TP and becomes stronger than before, leading to significantly northerly anomalies over the north of TP (Fig. 12d). Under such favorable circulation conditions, TFs occur over the eastern TP (Fig. 12d). From 1 to 3 August, with the further eastward movement of negative PV anomaly center over the north of TP, the entire SAH body (marked by 
$12520 \mathrm{gpm}$ ) stretches longitudinally and extends eastward (Figs. 12d-e). Meanwhile, the related northerly anomaly center moves from the north of TP to the northeast of TP (Figs. 12d-e). Till 3 August, the TF-ETP occurs (Fig. 12e).

To further examine the existence of such remote linkage between the TF-ETP and leading atmospheric perturbations over the NEA during this TF-ETP case, we plot in Fig. 13 the geopotential height and its anomalies, and wave activity flux anomalies at $200-\mathrm{hPa}$. As will be shown below, the remote linkage via a RWT can be verified in this typical TF-ETP case. Specifically, it can be seen from Fig. 13a that, a low anomaly center appears over the NEA since 26 July, and seems to act as the wave source of a RWT propagating downstream to Caspian Sea region. In addition, locations of the height anomaly centers along the RWT, as well as the wave activity flux anomaly pattern, are very similar to those in the regressed results shown in Fig. 6b. On 30 July, the propagating RWT induces an anomalous high to the northwest of Korean Peninsula, indicating a complete RWT stretching from the NEA to East Asia (Fig. 13c). When the anomalous low over the NEA tends to gradually decrease after 30 July, the high anomaly center over Western Europe gradually increases and seems to become the main wave source of the RWT (Figs. 13c-e). The RWT thus links the low anomaly over the NEA to the TF-ETP occurrence.

\section{Summary}

By identifying TF-ETP events objectively, this study performs a comprehensive composite and regressed analysis of TF-ETP occurred in the latest decades. We first reveal the significant and typical impacts of TF-ETP occurrence on the circulation 
and weather anomalies over East Asia, and then demonstrate that the TF-ETP occurrence is closely related to an intensification of the SAH center over TP, which in turn can be remotely connected to circulation anomalies over the NEA. Specifically, although the frequency of TF-ETP occurrence is only about 3\%, relatively lower than the two hot TFs spots over the eastern Mediterranean region (10\%) and the central Asian region $(8 \%)$ in summer, impacts of the TF-ETP occurrence, however, are critical in China and East Asia. Frequent TF-ETP occurrence is associated with a dipole rainfall anomaly pattern in China, with significantly negative rainfall anomalies in the upper and middle reaches of the Yangtze and Yellow river valleys, and positive rainfall anomalies in eastern China. In addition, Frequent TF-ETP occurrence corresponds to a significantly stronger SAH center over TP, which in turn induces anomalously strong upper-tropospheric northerlies and downward motion over the northeast of TP, and thus enhanced southward and downward PV intrusion to the east of TP.

Furthermore, the occurrence of TF-ETP, as well as the accompanied variation of the SAH, is connected to leading circulation anomalies over the NEA several days before via a RWT initiated from there. Around one week before the occurrence of TF-ETP, a low anomaly center over the NEA becomes the strongest. This anomalous low acts as the wave source of a RWT that propagates downstream along the SWJ. A downstream high anomaly center is induced over the Caspian Sea region, which gradually intensifies and moves eastward along the RWT. When this high anomaly center arrives at the north edge of the SAH, it helps to intensify the SAH center and 
forces it to shift eastward to the TP region. An anomalously stronger SAH center over TP thus favors the TF-ETP occurrence because of the anomalously stronger southward and downward PV intrusion caused by the stronger northerlies and descent motion over the east of TP. Furthermore, the close relationship between TF-ETP occurrence and SAH intensity, the rainfall anomaly pattern over East Asia during the period of TF-ETP occurrence, as well as the remote connection to the circulation anomalies over the NEA, are all verified in a typical TF-ETP case occurred in summer 1990.

It should be noted that the TF-ETP-related RWT identified here may be related to the recurrent teleconnection pattern which usually originates from the North Atlantic region and goes along the SWJ across the Eurasian continent in boreal summer (Ding and Wang 2005, 2007). In fact, some similar RWTs linking atmospheric perturbations over North Atlantic to the circulation anomalies over Eurasian continent were also identified in the intraseasonal and interannual timescales in boreal summer (e.g., Chang et al. 2001; Hu et al. 2016; Yang and Li 2016; Zhu et al. 2018). This study further demonstrates that the RWT is initiated from a low anomaly center over the NEA, which may be induced by the anomalously stronger dynamical forcing of transient eddy activities at the right side of the exit region of the North American SWJ. The occurrence of TF-ETP is thus remotely related to the circulation anomalies over the NEA. 
518 Research Program [grant number XDA17010105] of the Chinese Academy of

519 Sciences, the National Natural Science Foundation of China [grant numbers $520 \quad 91837311,91437105]$.

521 Funding This work was funded by the Strategic Priority Research Program [grant 522 number XDA17010105] of the Chinese Academy of Sciences, the National Natural 523 Science Foundation of China [grant numbers 91837311, 91437105].

Data availability The ERA-interim reanalysis dataset can be accessed from the website http://apps.ecmwf.int/datasets/data/interim-full-daily/levtype=sfc/. The CPC precipitation dataset can be accessed from the website https://www.esrl.noaa.gov/psd/data/gridded/data.cpc.globalprecip.html.

Code availability All the codes are programmed by NCAR Command Language 529 (NCL, version 6.6). The codes are available and maintained by Chuandong Zhu 530 (zcd@lasg.iap.ac.cn).

Authors' contributions Conceptualization: CDZ and RCR; methodology, CDZ and RCR; software, CDZ; formal analysis, CDZ and RCR; investigation, CDZ and RCR; resources, CDZ; writing-original draft preparation, CDZ; writing-review and editing, RCR; visualization, CDZ; supervision, RCR. All authors read and approved the final manuscript. 


\section{References}

Akritidis, D., et al. (2016), On the role of tropopause folds in summertime tropospheric ozone over the eastern Mediterranean and the Middle East, Atmos. Chem. Phys., 16, 14025-14039, doi:10.5194/acp-16-14025-2016.

Akritidis, D., A. Pozzer, and P. Zanis (2019), On the impact of future climate change on tropopause folds and tropospheric ozone, Atmos. Chem. Phys., 19, 14387-14401, doi:10.5194/acp-19-14387-2019.

Allen, J. T., A. B. Pezza, and M. T. Black (2010), Explosive cyclogenesis: A global climatology comparing multiple reanalyses, J. Clim., 23, 6468-6484, doi:10.1175/2010JCLI3437.1.

Antonescu, B., G. Vaughan, and D.M. Schultz (2013), A Five-Year Radar-Based Climatology of Tropopause Folds and Deep Convection over Wales, United Kingdom, Mon. Wea. Rev., 141, 1693-1707, doi:10.1175/MWR-D-12-00246.1.

Baray, J. L., V. Daniel, G. Ancellet, and B. Legras (2000), Planetary-scale tropopause folds in the southern subtropics, Geophys. Res. Lett., 27, 353-356, doi:10.1067/mai.2000.108430.

Bjerknes, J., and E. Palmén (1937), Investigations of selected European cyclones by means of serial ascents, Geophys. Publ., 12, 1-62.

Blackmon, M. L. (1976), A climatological spectral study of the $500 \mathrm{mb}$ geopotential height of the Northern Hemisphere, J. Atmos. Sci., 33, 1607-1623, doi: 10.1175/1520-0469(1976)0332.0.CO;2.

Bourqui, M. S. and P. Y. Trepanier (2010), Descent of deep stratospheric intrusions during the IONS August 2006 campaign, J. Geophys. Res., 115, doi:10.1029/2009JD013183.

Browning, K. A., and B. W. Golding (1995), Mesoscale aspects of a dry intrusion within a vigorous cyclone, Quart. J. Roy. Meteor. Soc., 121, 463-493, doi:10.1002/qj.49712152302.

Browning, K. A., and R. Reynolds (1994), Diagnostic study of a narrow cold-frontal rainband and severe winds associated with a stratospheric intrusion, Quart. J. Roy. Meteor. Soc., 120, 235-257, doi:10.1002/qj.49712051602.

Chen, M., et al. (2008), Assessing objective techniques for gauge-based analyses of global daily precipitation, J. Geophys. Res., 113, D04110, doi:10.1029/2007JD009132.

Chen, P. (1995), Isentropic cross-tropopause mass exchange in the extratropics, $J$. Geophys. Res., 100, 16661-16673, doi:10.1029/95JD01264.

Cooper, O. R., et al. (2005), Direct transport of midlatitude stratospheric ozone into the lower troposphere and marine boundary layer of the tropical Pacific Ocean, $J$. 
Geophys. Res., 110, 23310(1-15), doi:10.1029/2005JD005783.

Cui, Q., C. M. Wang, and Y. Zhang (2016), Analysis of impact of dry intrusion in a strong squall line process in eastern China, Desert and Oasis-Meteorology (in Chinese), 10, 18-24, doi:10.3969/j.issn.1002-0799.2016.02.003.

Dafka, S., D. Akritidis, P. Zanis, et al. (2020), On the link between the Etesian winds, tropopause folds and tropospheric ozone over the Eastern Mediterranean during summer. Atmos. Environ., 248, 1-12, doi:10.1016/j.atmosres.2020.105161.

Dee, D. P., et al. (2011), The ERA-Interim reanalysis: Configuration and performance of the data assimilation system, Quart. J. Roy. Meteor. Soc., 137, 553-597, doi:10.1002/qj.828.

Ding, Q. H., and B. Wang (2007), Intraseasonal teleconnection between the summer Eurasian wave train and the Indian monsoon, J. Clim., 20, 3751-3767, doi:10.1175/JCLI4221.1.

Ding, Q. H., and B. Wang (2005), Circumglobal teleconnection in the Northern hemisphere summer, J. Clim., 18, 3483-3505, doi:10.1175/JCLI3473.1.

Ebel, A., et al. (1991), Simulation of ozone intrusion caused by a tropopause fold and cut-off low, Atmos. Environ., 25, 2131-2144, doi:10.1016/0960-1686(91)90089-P.

Elbern, H., J. Hendricks, and A. Ebel (1998), A climatology of tropopause folds by global analyses, Theor. Appl. Climatol., 59, 181-200, doi:10.1007/s007040050023.

Ertel, H. (1942), A new hydrodynamical vorticity equation, Meteorologische Zeitschrift, 59, 33-49.

Fadnavis, S. and R. Chattopadhyay (2017), Linkages of Subtropical Stratospheric Intraseasonal Intrusions with Indian Summer Monsoon Deficit Rainfall, J. Clim., 30, 5083-5095, doi:10.1175/JCLI-D-16-0463.1.

Forster, C., and V. Wirth (2000), Radiative decay of idealized stratospheric filaments in the troposphere, J. Geophys. Res., 105, 10169-10184, doi:10.1029/2000JD900052.

Goering, M. A., W. A. Gallus, M. A. Olsen, and J. L. Stanford (2001), Role of stratospheric air in a severe weather event: Analysis of potential vorticity and total ozone, J. Geophys. Res., 106, 11813-11823, doi:10.1029/2000JD900651.

Gouget, H., G. Vaughan, A. Marenco, and H. G. J. Smit (2000), Decay of a cut-off low and contribution to stratosphere-troposphere exchange, Quart. J. Roy. Meteor. Soc., 126, 1117-1141, doi:10.1002/qj.49712656414.

Griffiths, M., A. J. Thorpe, and K. A. Browning (2000), Convective destabilization by a tropopause fold diagnosed using potential-vorticity inversion, Quart. J. Roy. Meteor. Soc., 126, 125-144, doi:10.1002/qj.49712656207. 
Hofmann, C., et al. (2016), Stratosphere-troposphere exchange in the vicinity of a tropopause fold, Atmos. Chem. Phys, 1-26, doi:10.5194/acp-2015-949.

Holopainen, E. O., L. Rontu, and N. C. Lau (1982), The effect of large-scale transient eddies on the time-mean flow in the atmosphere, J. Atmos. Sci., 39, 1972-1984, doi:10.1175/1520-0469(1982)0392.0.CO;2.

Holton, J. R., P. H. Haynes, M. E. McIntyre, A. R. Douglass, R. B. Rood, and L. Pfister (1995), Stratosphere-troposphere exchange, Rev. Geophys., 33, 403-440, doi:10.1029/95RG02097.

Hoskins, B. J., M. Pedder, and D. W. Jones (2003), The omega equation and potential vorticity, Quart. J. Roy. Meteor. Soc., 129, 3277-3303, doi:10.1256/qj.02.135.

Hoskins, B. J. (1997), A potential vorticity view of synoptic development, Meteor. Appl., d, 325-334, doi:10.1017/S1350482797000716.

Hoskins, B. J., and T. Ambrizzi (1993), Rossby Wave Propagation on a Realistic Longitudinally Varying Flow, J. Atmos. Sci., 50, 1661-1671, doi:10.1175/1520-0469(1993)050<1661:RWPOAR>2.0.CO;2.

Hoskins, B. J., P. J. Valdes (1990), On the existence of storm-tracks, J. Atmos. Sci., 47, 1854-1864, doi:10.1175/1520-0469(1990)047<1854:OTEOST>2.0.CO;2.

Hoskins, B. J., M. E. McIntyre, and A. W. Robertson (1985), On the use and significance of isentropic potential vorticity maps, Quart. J. Roy. Meteor. Soc., 111, 877-946, doi:10.1002/qj.49711147002.

Hoskins, B. J., and D. J. Karoly (1981), The steady linear response of a spherical atmosphere to thermal and orographic forcing, J. Atmos. Sci., 38, 1179-1196, doi:10.1175/1520-0469(1981)038<1179:TSLROA>2.0.CO;2.

Hsu, C. J., R. A. Plumb (2000), Nonaxisymmetric thermally driven circulations and upper-tropospheric monsoon dynamics, J. Atmos. Sci., 57, 1255-1276, doi:10.1175/1520-0469(2000)057<1255:NTDCAU>2.0.CO;2.

$\mathrm{Hu}, \mathrm{W} . \mathrm{T}$, , et al. (2016) The intraseasonal oscillation of eastern Tibetan Plateau precipitation in response to the summer Eurasian wave train, J. Clim., 29, 7215-7230, doi:10.1175/JCLI-D-15-0620.1.

Keyser, D., and M. A. Shapiro (1986), A review of the structure and dynamics of upper-level frontal zones, Mon. Wea. Rev., 114, 452-499, doi:10.1175/1520-0493(1986)114<0452:AROTSA>2.0.CO;2.

Kim, J., et al. (2013), A Case Study of Mesoscale Snowfall Development Associated with Tropopause Folding, Atmos., 23, 331-346, doi:10.14191/Atmos.2013.23.3.331.

Krishnamurti, T. N., and H. N. Bhalme (1976), Oscillations of a monsoon system. Part I. observational aspects. J. Atmos. Sci., 33, 1937-1954, doi:10.1175/1520-0469(1976)033\%3C1937:OOAMS P\%3E2.0.CO;2. 
Krishnamurti, T. N., and P. Ardanuy (1980), The 10 to 20-day westward propagating mode and "Breaks in the Monsoons, Tellus, 1, 15-26, doi:10.3402/tellusa.v32i1.10476.

Lamarque, J. F., and P. G. Hess (1994), Cross-tropopause mass exchange and potential vorticity budget in a simulated tropopause folding, J. Atmos. Sci., 51, 2246-2269, doi:10.1175/1520-0469.

Lau, N. C. (1978). On the three-dimensional structure of the observed transient eddy statistics of the northern Hemisphere wintertime circulation, J. Atmos. Sci., 35, 1854-1864, doi:10.1175/1520-0469(1978)035<1900:OTTDSO>2.0.CO;2.

Lau, N. C., and E. O. Holopainen (1984), Transient eddy forcing of the time-mean flow as identified by geopotential tendencies, J. Atmos. Sci., 41, 313-328, doi:10.1175/1520-0469(1984)041,0313:TEFOTT.2.0.CO;2.

Lau, N. C., and M. J. Nath (1991), Variability of the baroclinic and barotropic transient eddy forcing associated with monthly changes in the midlatitude storm tracks, J. Atmos. Sci., 48, 258-2613, doi:10.1175/1520-0469(1991)048,2589:VOTBAB.2.0.CO;2.

Lelieveld, J., and F. J. Dentener (2000), What controls tropospheric ozone? J. Geophys. Res., 105, 3531-3551, doi:10.1029/1999JD901011.

Liu, H. R., and C. Y. Li (2010), Impacts of the Dry Intrusion on Jinan Torrential Rain Occurring on 18 July 2007, Chin. J. Atmos. Sci. (in Chinese), 34, 374-386, doi:10.3878/j.issn.1006-9895.2010.02.11.

Liu, Y. M., et al. (2001), Condensation heating of the Asian summer monsoon and the subtropical anticyclone in the Eastern Hemisphere, Clim. Dyn., 17, 327-338, doi:10.1007/s003820000117.

Liu, Y. M., B. J. Hoskins, and M. Blackburn (2007), Impact of Tibetan orography and heating on the summer flow over Asia, J. Meteor. Soc. Jpn., 85, 1-19, doi:10.2151/jmsj.85B.1.

Morcrette, C., et al. (2007), Combination of Mesoscale and Synoptic Mechanisms for Triggering an Isolated Thunderstorm: Observational Case Study of CSIP IOP 1, Mon. Wea. Rev., 135, 3728-3749, doi:10.1175/2007MWR2067.1.

Mullen, S. L. (1987), Transient eddy forcing of blocking flows, J. Atmos. Sci., 44, 3-22, doi:10.1175/1520-0469(1987)044,0003:TEFOBF.2.0.CO;2.

Ortega, S., et al. (2017), Quasi-biweekly oscillations of the South Asian monsoon and its co-evolution in the upper and lower troposphere, Clim. Dyn., 49, 1-16, doi:10.1007/s00382-016-3503-y.

Plumb, R. A. (1985), On the three-dimensional propagation of stationary waves, $J$. Atmos. Sci., 42, 217-229, doi:10.1175/1520-0469(1985)042<0217:OTTDPO >2.0.CO;2. 
Popovic, J. M., R. A. Plumb (2001), Eddy Shedding from the Upper-Tropospheric Asian Monsoon Anticyclone, J. Atmos. Sci., 58, 93-105, doi:10.1175/1520-0469(2001)058<0093:ESFTUT>2.0.CO;2.

Reed, R. J. (1955), A study of a characteristic type of upper-level frontogenesis, $J$. Atmos. Sci., 12, 226-237, doi:10.1175/1520-0469(1955)012<0226:ASOACT >2.0.CO;2.

Ren, R. C., et al. (2014), Progresses in stratosphere-troposphere interactions: application of isentropic potential vorticity dynamics and effect of the Tibetan Plateau, J. Meteor. Res., 28 714-731, doi:10.1007/s13351-014-4026-2.

Ren, R. C., C. D. Zhu, and M. Cai (2019), Linking quasi-biweekly variability of the South Asian high to atmospheric heating over Tibetan Plateau in summer, Clim. Dyn., 53, 3419-3429, doi:10.1007/s00382-019-04713-4.

Ren, X. J., D. Yang, X. Q. Yang (2015), Characteristics and mechanism of subseasonal eastward extension of South Asian high, J. Clim., 28, 6799-6822, doi:10.1175/JCLI-D-14-00682.1.

Russell, A., G. Vaughan, and E. G. Norton (2012), Large-scale potential vorticity anomalies and deep convection, Quart. J. Roy. Meteor. Soc., 138, 1627-1639, doi:10.1002/qj.1875.

Sanders, F., and J. R. Gyakum (1980), Synoptic-dynamic climatology of the "bomb", Mon. Wea. Rev., 108, 1589-1606, doi:10.1175/1520-0493(1980)1082.0.CO;2.

Sawyer, J. S. (1956), The vertical circulation at meteorological fronts and its relation to frontogenesis, Proc. R. Soc. Lond. A, 234, 346-362, doi:10.1098/rspa.1956.0039.

Schmidt, T., et al. (2006), A climatology of multiple tropopauses derived from GPS radio occultations with CHAMP and SAC-C, Geophys. Res. Lett., 33, L04808, doi:10.1029/2005GL024600.

Shapiro, M. A. (1981), Frontogenesis and geostrophically forced secondary circulations in the vicinity of jet stream-frontal zone systems, J. Atmos. Sci, 38, 954-973, doi:10.1175/1520-0469(1981)038<0954:FAGFSC >2.0.CO;2.

Shapiro, M. A. (1980), Turbulent mixing within tropopause folds as a mechanism for the exchange of chemical constituents between the stratosphere and troposphere, J. Atmos. Sci., 37, 994-1004, doi:10.1175/1520-0469(1980)037<0994:TMWTFA>2.0.CO;2.

Shou, Y. X., et al. (2014), A New Method for Tropopause Folding Detection and Its Application in Middle-Latitude Disastrous Weather Forecasting, Chin. J. Atmos. Sci. (in Chinese), 38, 1109-1123, doi:10.3878/j.issn.1006-9895.1403.13258.

Škerlak, B., et al. (2015), Tropopause folds in ERA-Interim: Global climatology and relation to extreme weather events, J. Geophys. Res., 120, 4860-4877, 
Škerlak, B., M. Sprenger, and H. Wernli (2014), A global climatology of stratosphere-troposphere exchange using the ERA-Interim data set from 1979 to 2011, Atmos. Chem. Phys., 14, 913-937, doi:10.5194/acp-14-913-2014.

Sorensen, J. H., and N. W. Nielsen (2001), Intrusion of stratospheric ozone to the free troposphere through tropopause folds - A case study, Phys. Chem., 26, 801-806, doi:10.1016/S1464-1909(01)00088-0.

Sprenger, M., M. C. Maspoli, and H. Wernli (2003), Tropopause folds and cross-tropopause exchange: a global investigation based upon ecmwf analyses for the time period march 2000 to february 2001, J. Geophys. Res, 108, 8518, doi:10.1029/2002JD002587, 2003.

Stohl, A., et al. (2003), Stratosphere-troposphere exchange: a review, and what we have learned from staccato, J. Geophys. Res., 108, 469-474, doi:10.1029/2002JD002490.

Terao, T. (1999), The Zonal Wavelength of the Quasi-Stationary Rossby Waves Trapped in the Westerly Jet, J. Meteor. Soc. Jpn., 77, 687-699, doi:10.2151/jmsj1965.77.3_687.

Thorpe, A. J. (1997), Attribution and its application to mesoscale structure associated with tropopause folds, Quart. J. Roy. Meteor. Soc., 123, 2377-2399, doi:10.1002/qj.49712354411.

Traub, M., and J. Lelieveld (2003), Cross-tropopause transport over the eastern Mediterranean, J. Geophys. Res., 108, 4712, doi:10.1029/2003JD003754.

Tyrlis, E., et al. (2014), On the linkage between the Asian summer monsoon and tropopause fold activity over the eastern Mediterranean and the Middle East, $J$. Geophys. Res., 119, 3202-3221, doi:10.1002/2013JD021113.

Tyrlis, E., J. Lelieveld, and B. Steil (2013), The summer circulation over the eastern Mediterranean and the Middle East: influence of the South Asian monsoon, Clim. Dyn., 40, 1103-1123, doi:10.1007/s00382-012-1528-4.

Uccellini, L. W. (1990), Processes contributing to the rapid development of extratropical cyclones, in Extratropical Cyclones, The Erik Palmén Memorial Volume, edited by C. Newton and E. Holopainen, pp. 81-105, Am. Meteorol. Soc., Boston, Mass.

Vaughan, G., et al. (2017), Invigoration and Capping of a Convective Rainband ahead of a Potential Vorticity Anomaly, Mon. Wea. Rev., 145, 2093-2117, doi : 10.1175/MWR-D-16-0397.1.

Vogel, B., et al. (2014), Fast transport from Southeast Asia boundary layer sources to northern Europe: rapid uplift in typhoons and eastward eddy shedding of the Asian monsoon anticyclone, Atmos. Chem. Phys., 14, 12745-12762, 
doi:10.5194/acpd-14-18461-2014.

Wernli, H., S. Dirren, M. A. Liniger, and M. Zillig (2002), Dynamical aspects of the life cycle of the winter storm "Lothar" (24-26 December 1999), Quart. J. Roy. Meteor. Soc., 128, 405-429, doi:10.1256/003590002321042036.

Wu, G. X., and Y. M. Liu (2000), Thermal adaptation, dispersion, and subtropical anticyclone Part I: Thermal adaptation and overshooting, Chi. J. Atmos. Sci. (in Chinese), 24, 433-446, doi:10.3878/j.issn.1006-9895.2000.04.01.

Wu, Y. T., et al. (2018), On the linkage between the Asian summer monsoon and tropopause folds, J. Geophys. Res., 123, 2037-2049. doi:10.1002/2017JD027870.

Xia, X., et al. (2016), An analysis on the spatio-temporal variations and dynamic effects of the tropopause and the related stratosphere-troposphere coupling surrounding the Tibetan Plateau area, Acta Meteor. Sin., 74, 525-541, doi:10.11676/qxxb2016.036.

Xu, P. Q., L. Wang, and W. Chen (2018), The British-Baikal Corridor: A teleconnection pattern along the summertime polar front jet over Eurasia, $J$. Clim., 32, 877-896, doi:10.1175/JCLI-D-18-0343.1.

Yanai, M., E. Steven, and J. H. Chu (1973), Determination of bulk properties of tropical cloud clusters from large-scale heat and moisture budgets, J. Atmos. Sci., 30, 611-627, doi:10.1175/1520-0469(1973)030<0611:DOBPOT>2.0.CO;2.

Yang, S. Y., T. Li (2016), Zonal shift of the South Asian High on the subseasonal time-scale and its relation to the summer rainfall anomaly in China, Quart. J. Roy. Meteor. Soc., 142, 2324-2335, doi:10.1002/qj.2826.

Zhao, D. J., and X. P. Yao (2017), Characteristics of the Dry Intrusion Index in an extreme torrential rain event occurred on 21 July 2012 in Beijing, Torrential Rain and Disasters (in Chinese), 36, 527-534, doi:10.3969/j.issn.1004-9045.2017.06.005.

Zhu, C. D., R. C. Ren, and G. X. Wu (2018), Varying Rossby wave trains from the developing to decaying period of the upper atmospheric heat Source over the Tibetan Plateau in boreal summer, Adv. Atmos. Sci., 35, 1114-1128, doi:10.1007/s00376-017-7231-y. 


\section{Figure Captions}

Fig. 1 (a) Summertime (July-August) climatology of tropopause folding frequency (shaded; units: \%), geopotential height (brown contours; units: gpm; interval: 10) and westerly jet speed (black contours; units: $\mathrm{m} \mathrm{s}^{-1}$; above $20 \mathrm{~m} \mathrm{~s}^{-1}$ ) at $200-\mathrm{hPa}$. The TP's topographic boundary of $1500 \mathrm{~m}$ is marked with thin black solid line, and the Yellow and Yangtze River from north to south is marked with blue lines. (b) Daily variation of the TFI for the 40 summers (July-August). The abscissa represents the time in year and the vertical red dashed lines indicate 1 July of every year. (c) Power spectrum (solid line) of the normalized daily TFI derived from data in the 40 summers. The short and long dashes mark the $99 \%$ confidence level and the red noise spectrum respectively.

Fig. 2 Vertical cross-sections of ( $a, b)$ composite potential temperature (red dashed contours; units: K; interval: 10), PV (blue contours; units: PVU; only values of 1 and

8352 PVU are plotted) and its anomalies (shaded; units: PVU); and (c, d) composite 836 horizontal divergence anomalies (black contours; units: $10^{-6} \mathrm{~s}^{-1}$; interval: 1 ; value of 
zero is neglected), vertical motion $\omega$ (shaded; units: $10^{-2} \mathrm{~Pa} \mathrm{~s}^{-1}$ ) anomalies and PV (blue contours; units: PVU; only values of 1 and 2 PVU are plotted) for high TFI days. The left and right column are for the vertical-longitudinal cross-section along $39^{\circ} \mathrm{N}$ and the vertical-latitudinal cross-section along $111^{\circ} \mathrm{E}$ respectively. Black contours in $(\mathrm{a}, \mathrm{b})$ denote the corresponding summer climatology of 1 and 2 PVU surfaces. Stippled in (a, b) and (c, d) indicate the 90\% confidence level of the composite potential vorticity anomalies and vertical motion anomalies respectively. Areas shaded in black show the topography.

Fig. 3 Composites of (a) PV anomalies (shaded; units: PVU; only those above 90\% confidence level are plotted) and horizontal wind anomalies (vector; units: $\mathrm{m} \mathrm{s}^{-1}$ ) at 300-hPa; (b) horizontal divergence anomalies (shaded; units: $10^{-6} \mathrm{~s}^{-1}$ ) and horizontal wind anomalies (vector; units: $\mathrm{m} \mathrm{s}^{-1}$ ) at $700-\mathrm{hPa}$; (c) rainfall anomalies (shaded; units: $\mathrm{mm}$ ) for high TFI days. Stippling areas in (b) and (c) indicate the $90 \%$ confidence level of the composite horizontal divergence anomalies and rainfall anomaleis, respectively. Black arrows in (b) indicate the $90 \%$ confidence level of the composite horizontal wind anomalies.

Fig. 4 Composite TF frequency (shaded; units: \%), geopotential height (brown contours; units: gpm; interval: 10; 12520 gpm above) and westerly wind speed (black contours; units: $\mathrm{m} \mathrm{s}^{-1} ; 20 \mathrm{~m} \mathrm{~s}^{-1}$ above) at 200-hPa for high TFI days. The thin black solid contour marks the TP's topographic boundary of $1500 \mathrm{~m}$. The blue curves delineate the Yellow and Yangtze River from north to south.

Fig. 5 Composite (a) meridional wind (contours; units: $\mathrm{m} \mathrm{s}^{-1}$; interval: 1; Value of zero is neglected) and vertical motion $\omega$ (shaded; units: $10^{-2} \mathrm{~Pa} \mathrm{~s}^{-1}$ ) anomalies at $200-\mathrm{hPa}$; (b) geopotential height (brown contours; units: gpm; interval: 10; 12520 gpm above) and its anomalies (shaded; units: gpm), westerly wind speed (black contours; units: $\mathrm{m}$ $\mathrm{s}^{-1} ; 20 \mathrm{~m} \mathrm{~s}^{-1}$ above), and wave activity flux (vector; units: $10^{-1} \mathrm{~m}^{2} \mathrm{~s}^{-2}$; amplitudes larger than 0.05 are shown) anomalies at $200-\mathrm{hPa}$ for high TFI days. The Stippling and hatched areas in (a) indicate the $90 \%$ confidence level of composite meridional wind and vertical motion anomalies, respectively. The Stippling areas in (b) indicate the $90 \%$ confidence level of the composite geopotential height anomalies.

Fig. $6 \mathrm{Lead} / \mathrm{lag}$ regressions against the PVI of geopotential height (black contours; units: gpm; interval 4; value of zero is ignored), vertical motion $\omega$ (shaded; units: $10^{-2}$ $\mathrm{Pa} \mathrm{s}^{-1}$; only the statistical significance at $90 \%$ confidence level is plotted), and wave activity flux anomalies (vector; units: $10^{-1} \mathrm{~m}^{2} \mathrm{~s}^{-2}$; amplitudes larger than 0.5 are shown) at 200-hPa, when the PVI leads for (a) -7 days, (b) -6 days, (c) -5 days, (d) -4 days, (e) -3 days, (f) -2 days, (g) -1 day, and (h) 0 day. The red contours denote 
the westerly jet that is stronger than $20 \mathrm{~m} \mathrm{~s}^{-1}$ at $200-\mathrm{hPa}$. The stippling areas indicate the $90 \%$ confidence level of the regressed geopotential height anomalies.

Fig. 7 As in Fig. 6 but for the PV (shaded; units: PVU; statistical significance at 90\% confidence level), meridional PV advection (black contours; units: PVU s ${ }^{-1}$; interval: 0.4 ), and meridional wind anomalies (vector; units: $\mathrm{m} \mathrm{s}^{-1}$; only the vectors that are statistically significant at $95 \%$ confidence level are plotted ) at $200-\mathrm{hPa}$. The stippling areas indicate the $90 \%$ confidence level of the regressed meridional PV advection anomalies.

Fig. 8 (a) Temporal evolution of the lead regressions against the PVI from day -10 to day 0 , of transient eddy kinetic energy (shaded; units: $\mathrm{m}^{2} \mathrm{~s}^{-2}$ ) and vorticity advection (contours; units: $10^{-6} \mathrm{~m} \mathrm{~s}^{-2}$; interval 2) anomalies at 300-hPa along the northern North Atlantic $\left(32^{\circ}-58^{\circ} \mathrm{N}\right)$; (b) Geographical distribution of the regressed transient eddy kinetic energy (shaded; units: $\mathrm{m}^{2} \mathrm{~s}^{-2}$ ) and vorticity advection (contours; units: $10^{-6} \mathrm{~m}$ $\mathrm{s}^{-2}$; interval 2 ; value of zero is ignored) anomalies at $300-\mathrm{hPa}$ at day -7 . The red contours denote the westerly jet (units: $\mathrm{m} \mathrm{s}^{-1}$; interval: 4; values above 20 are plotted) at 300-hPa. Stipplings and slashes in (a) and b) indicate the $90 \%$ confidence level of the regressions respectively for the transient eddy kinetic energy and vorticity advection anomalies.

Fig. 9 Vertical cross sections of (a) the regressed horizontal divergence (shaded; units: $10^{-6} \mathrm{~s}^{-1}$ ), relative vorticity (contours; units: $10^{-6} \mathrm{~s}^{-1}$ ), and vertical motion $\omega$ anomalies (vectors; units: $10^{-3} \mathrm{~Pa} \mathrm{~s}^{-1}$ ); and (b) the regressed air temperature (shaded; units: ${ }^{\circ} \mathrm{C}$ ), and geopotential height (contours; units: gpm) anomalies against the PVI along $48^{\circ} \mathrm{N}$ over the northern North Atlantic at day -7 . Stipplings indicate the $90 \%$ confidence level of the regression for (a) the horizontal divergence anomalies and (b) the air temperature anomalies, respectively. The ordinate in $(a, b)$ is the pressure level (units: $\mathrm{hPa})$.

Fig. 10 Distribution of (a) the tropopause (2 PVU contour, bold brown), PV anomalies (shaded; units: PVU) on $350 \mathrm{~K}$ isentropic surface, and (b) horizontal wind anomalies (vector; units: $\mathrm{m} \mathrm{s}^{-1}$ ) at $700-\mathrm{hPa}$ and precipitation anomalies (shaded; units: $\mathrm{mm} \mathrm{d}^{-1}$ ) on 3 August, 1990.

Fig. 11 Vertical cross sections of $(a, b)$ potential temperature (red dashed contours; units: K; interval: 10), PV (blue contours; units: PVU; only values of 1 and 2 PVU are plotted) and its anomalies (shaded; units: PVU) on 3 August, 1990; and (c, d) horizontal divergence anomalies (black contours; units: $10^{-6} \mathrm{~s}^{-1}$; interval: 4; value of zero is neglected), vertical motion $\omega$ (shaded; units: $10^{-2} \mathrm{~Pa} \mathrm{~s}^{-1}$ ) anomalies and PV (blue contours; units: PVU; only values of 1 and 2 PVU are plotted) on 3 August, 1990. The left and right column are for the vertical-longitudinal cross-section along 
$37.5^{\circ} \mathrm{N}$ and the vertical-latitudinal cross-section along $109^{\circ} \mathrm{E}$ respectively. Black contours in $(a, b)$ are the corresponding summer climatology of 1 and 2 PVU. Areas shaded in black show the topography.

922

Fig. 12 Distribution of PV (shaded; units: PVU), the tropopause (2 PVU contour, bold brown) and the meridional wind anomalies (blue contours; units: $\mathrm{m} \mathrm{s}^{-1}$; interval: 6 ; value of zero is neglected) at $350 \mathrm{~K}$ isentropic surface, black dots mark the locations where tropopause folding occurred; And geopotential height at $200 \mathrm{hPa}$ (red contours; units: gpm; interval: 10; above 12520 gpm) on (a) 26 July, (b) 28 July, (c) 30 July, (d) 1 August and (e) 3 August, 1990, respectively.

934

935

936

937

938

939

940

Figures 

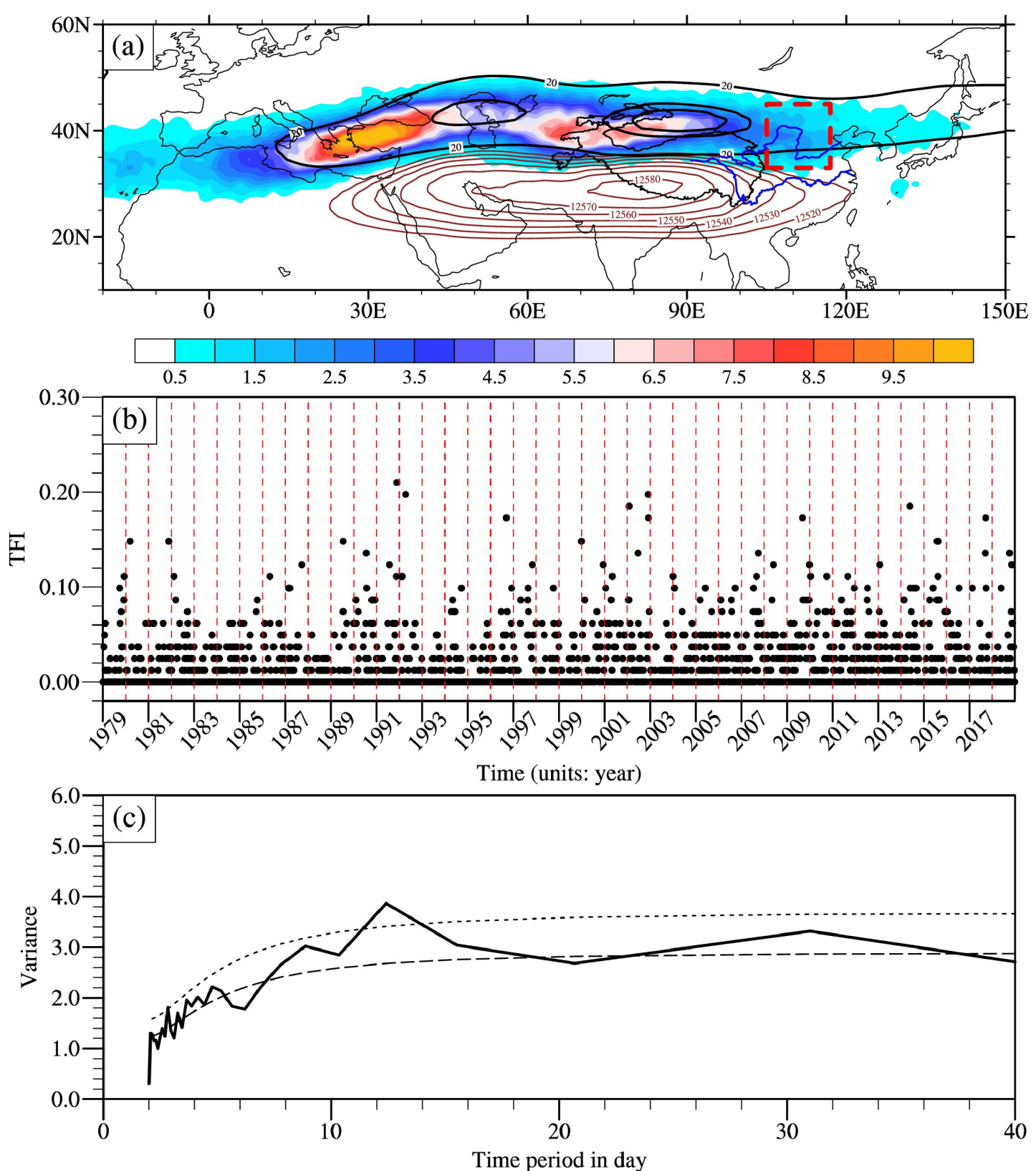

942 Fig. 1 (a) Summertime (July-August) climatology of tropopause folding frequency (shaded; units: \%), geopotential height (brown contours; units: gpm; interval: 10) and westerly jet speed (black contours; units: $\mathrm{m} \mathrm{s}^{-1}$; above $20 \mathrm{~m} \mathrm{~s}^{-1}$ ) at $200-\mathrm{hPa}$. The TP's topographic boundary of $1500 \mathrm{~m}$ is marked with thin black solid line, and the Yellow and Yangtze River from north to south is marked with blue lines. (b) Daily variation of the TFI for the 40 summers (July-August). The abscissa represents the time in year and the vertical red dashed lines indicate 1 July of every year. (c) Power spectrum (solid line) of the normalized daily TFI derived from data in the 40 summers. The short and long dashes mark the $99 \%$ confidence level and the red noise spectrum respectively. 

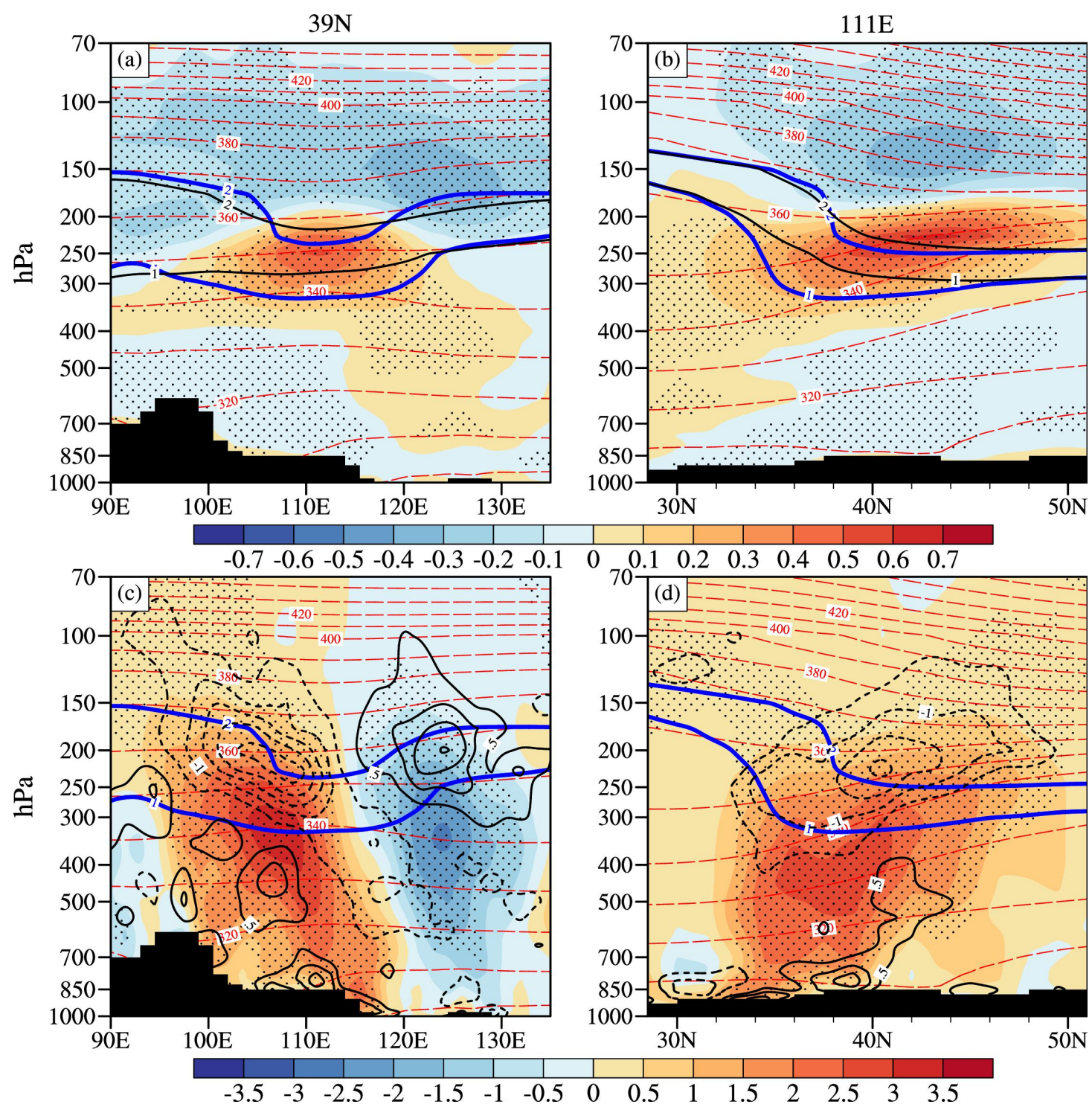

Fig. 2 Vertical cross-sections of (a, b) composite potential temperature (red dashed contours; units: K; interval: 10), PV (blue contours; units: PVU; only values of 1 and 2 PVU are plotted) and its anomalies (shaded; units: PVU); and (c, d) composite horizontal divergence anomalies (black contours; units: $10^{-6} \mathrm{~s}^{-1}$; interval: 1 ; value of zero is neglected), vertical motion $\omega$ (shaded; units: $10^{-2} \mathrm{~Pa} \mathrm{~s}^{-1}$ ) anomalies and PV (blue contours; units: PVU; only values of 1 and 2 PVU are plotted) for high TFI days. The left and right column are for the vertical-longitudinal cross-section along $39^{\circ} \mathrm{N}$ and the vertical-latitudinal cross-section along $111^{\circ} \mathrm{E}$ respectively. Black contours in $(\mathrm{a}, \mathrm{b})$ denote the corresponding summer climatology of 1 and 2 PVU surfaces. Stippled in $(\mathrm{a}, \mathrm{b})$ and $(\mathrm{c}, \mathrm{d})$ indicate the $90 \%$ confidence level of the composite potential vorticity anomalies and vertical motion anomalies respectively. Areas shaded in black show the topography. 

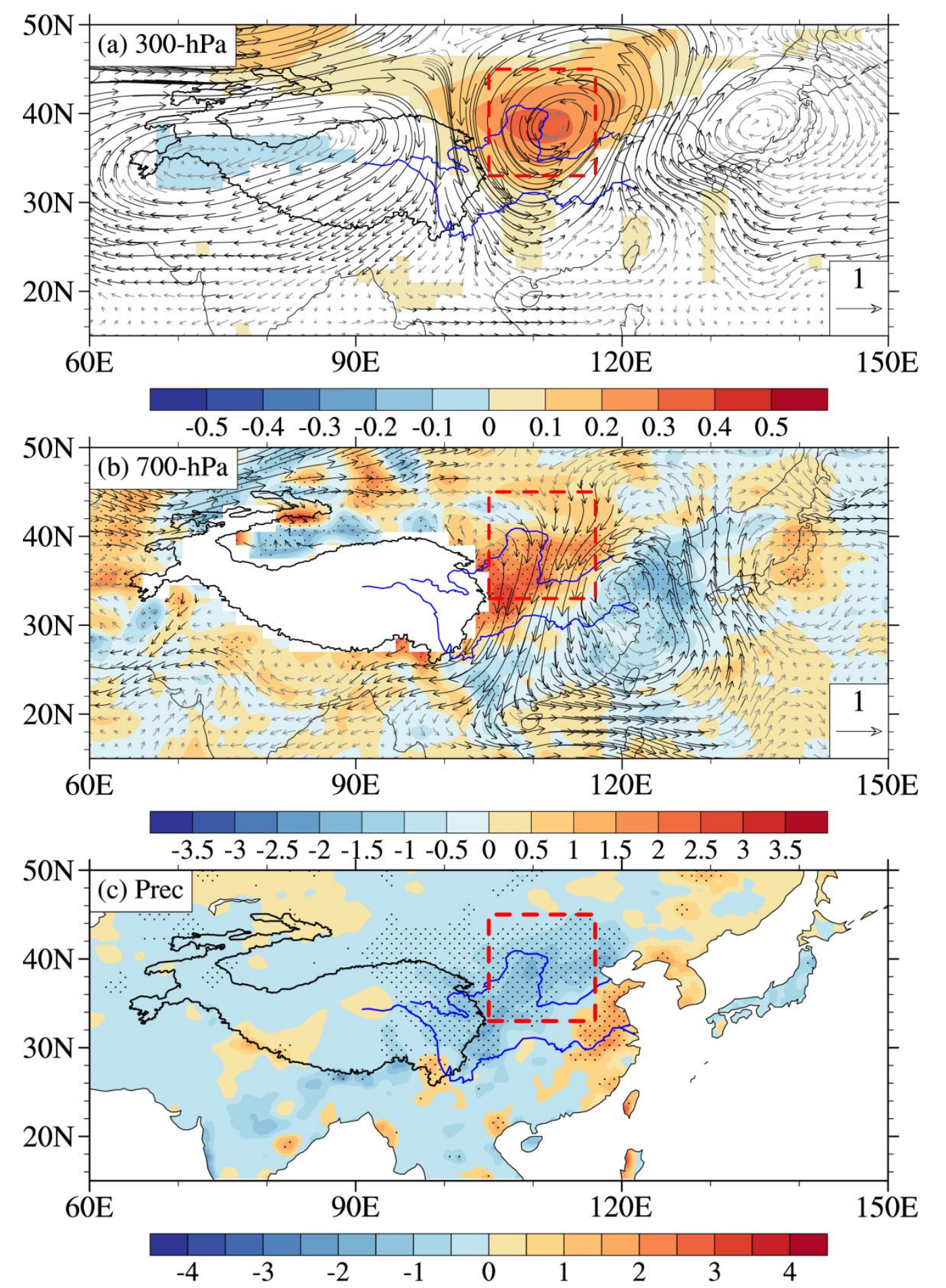

970 Fig. 3 Composites of (a) PV anomalies (shaded; units: PVU; only those above 90\% 971 confidence level are plotted) and horizontal wind anomalies (vector; units: $\mathrm{m} \mathrm{s}^{-1}$ ) at $972300-\mathrm{hPa}$; (b) horizontal divergence anomalies (shaded; units: $10^{-6} \mathrm{~s}^{-1}$ ) and horizontal 973 wind anomalies (vector; units: $\mathrm{m} \mathrm{s}^{-1}$ ) at 700-hPa; (c) rainfall anomalies (shaded; units: $\mathrm{mm}$ ) for high TFI days. Stippling areas in (b) and (c) indicate the $90 \%$ confidence level of the composite horizontal divergence anomalies and rainfall anomaleis,

976 respectively. Black arrows in (b) indicate the $90 \%$ confidence level of the composite horizontal wind anomalies. 


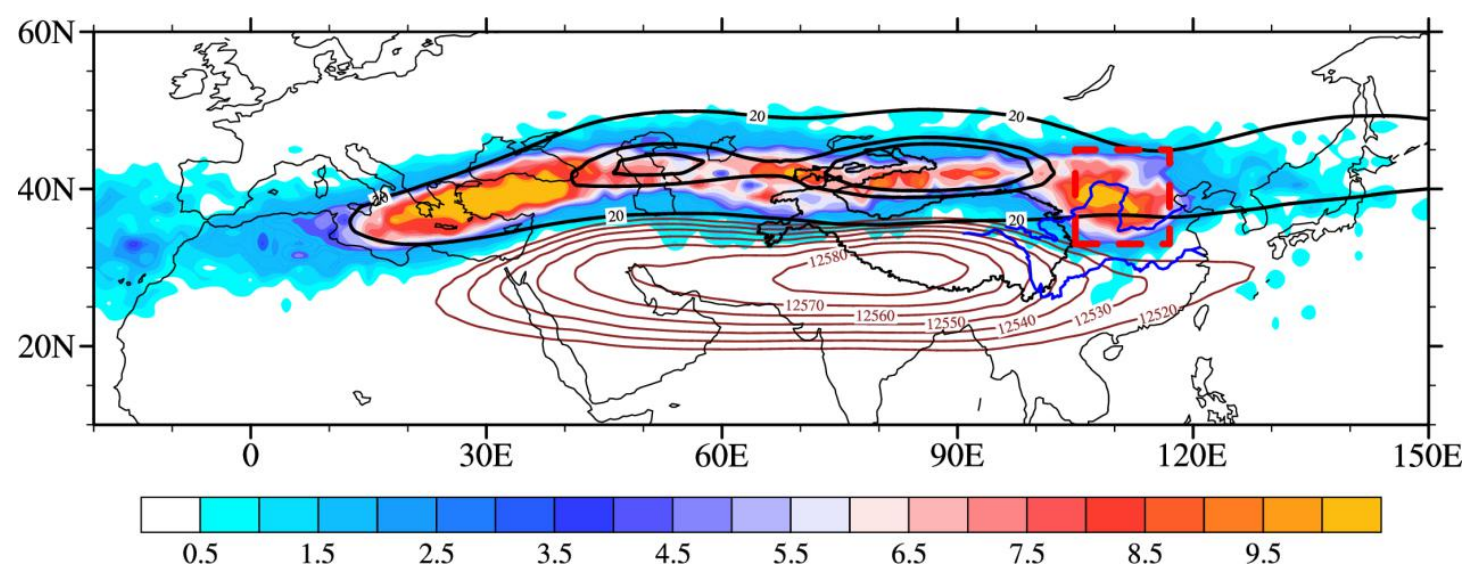

979 Fig. 4 Composite TF frequency (shaded; units: \%), geopotential height (brown 980 contours; units: gpm; interval: 10; 12520 gpm above) and westerly wind speed (black 981 contours; units: $\mathrm{m} \mathrm{s}^{-1} ; 20 \mathrm{~m} \mathrm{~s}^{-1}$ above) at 200-hPa for high TFI days. The thin black 982 solid contour marks the TP's topographic boundary of $1500 \mathrm{~m}$. The blue curves 983 delineate the Yellow and Yangtze River from north to south.

984

985

986

987

988

989

990

991

992

993

994

995

996

997

998

999

1000

1001

1002

1003

1004

1005

1006 

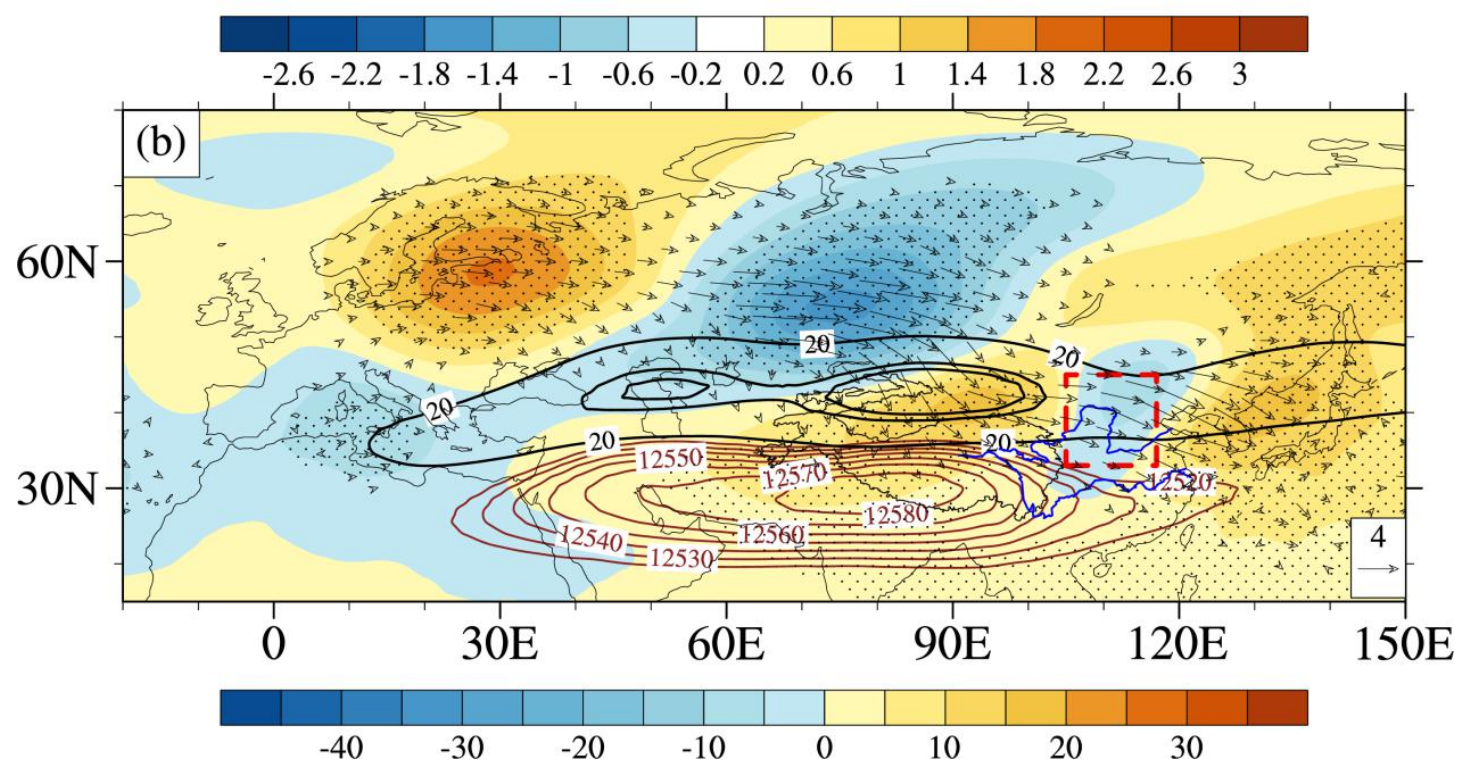

Fig. 5 Composite (a) meridional wind (contours; units: $\mathrm{m} \mathrm{s}^{-1}$; interval: 1; Value of zero is neglected) and vertical motion $\omega$ (shaded; units: $10^{-2} \mathrm{~Pa} \mathrm{~s}^{-1}$ ) anomalies at $200-\mathrm{hPa}$; (b) geopotential height (brown contours; units: gpm; interval: 10; 12520 gpm above) and its anomalies (shaded; units: gpm), westerly wind speed (black contours; units: $\mathrm{m}$ $\mathrm{s}^{-1} ; 20 \mathrm{~m} \mathrm{~s}^{-1}$ above), and wave activity flux (vector; units: $10^{-1} \mathrm{~m}^{2} \mathrm{~s}^{-2}$; amplitudes larger than 0.05 are shown) anomalies at $200-\mathrm{hPa}$ for high TFI days. The Stippling and hatched areas in (a) indicate the $90 \%$ confidence level of composite meridional wind and vertical motion anomalies, respectively. The Stippling areas in (b) indicate the $90 \%$ confidence level of the composite geopotential height anomalies. 

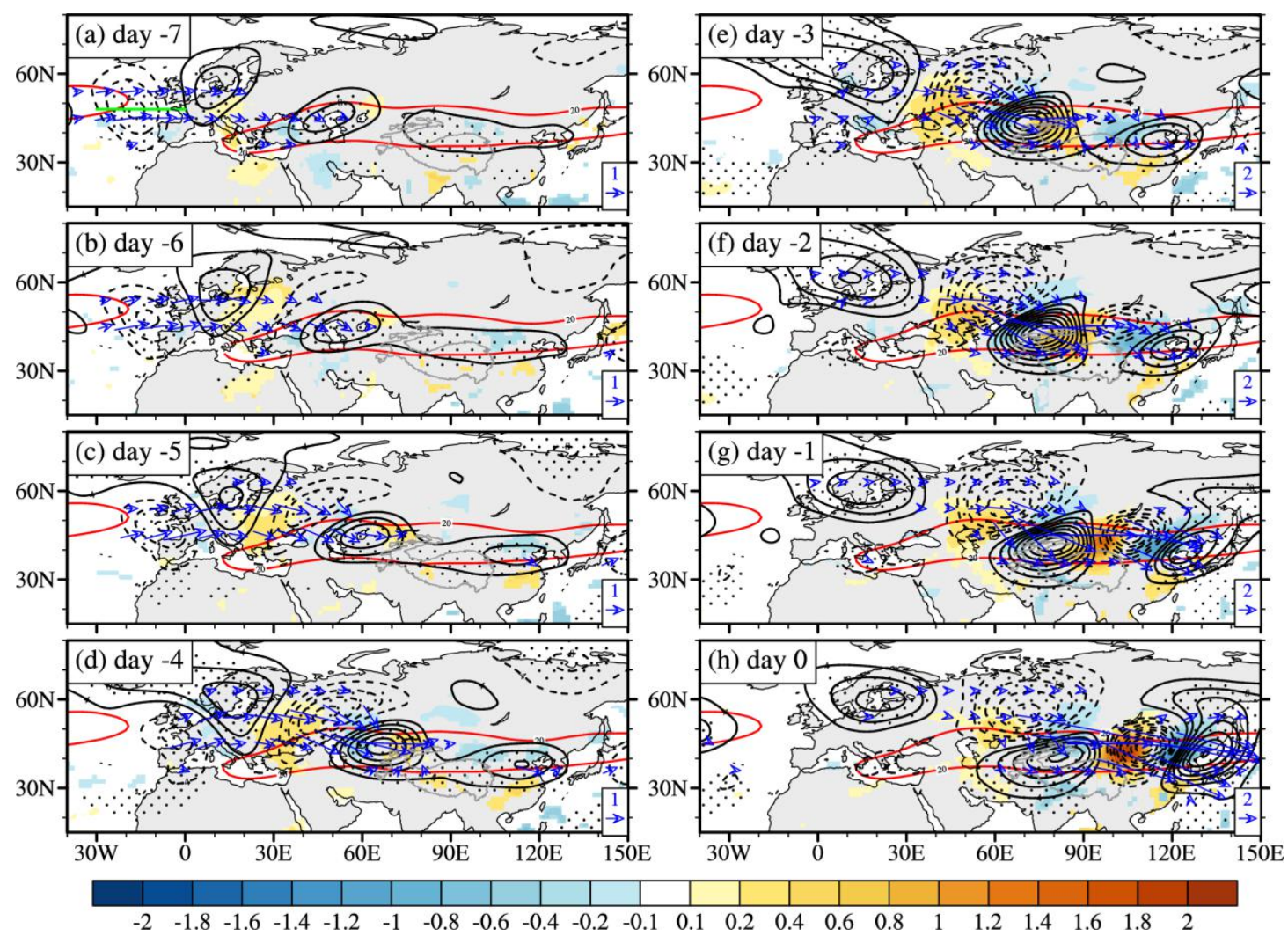

Fig. 6 Lead/lag regressions against the PVI of geopotential height (black contours; units: gpm; interval 4; value of zero is ignored), vertical motion $\omega$ (shaded; units: $10^{-2}$ $\mathrm{Pa} \mathrm{s}^{-1}$; only the statistical significance at $90 \%$ confidence level is plotted), and wave activity flux anomalies (vector; units: $10^{-1} \mathrm{~m}^{2} \mathrm{~s}^{-2}$; amplitudes larger than 0.5 are shown) at 200-hPa, when the PVI leads for (a) - 7 days, (b) -6 days, (c) -5 days, (d) -4 days, (e) -3 days, (f) -2 days, (g) -1 day, and (h) 0 day. The red contours denote the westerly jet that is stronger than $20 \mathrm{~m} \mathrm{~s}^{-1}$ at $200-\mathrm{hPa}$. The stippling areas indicate the $90 \%$ confidence level of the regressed geopotential height anomalies. 


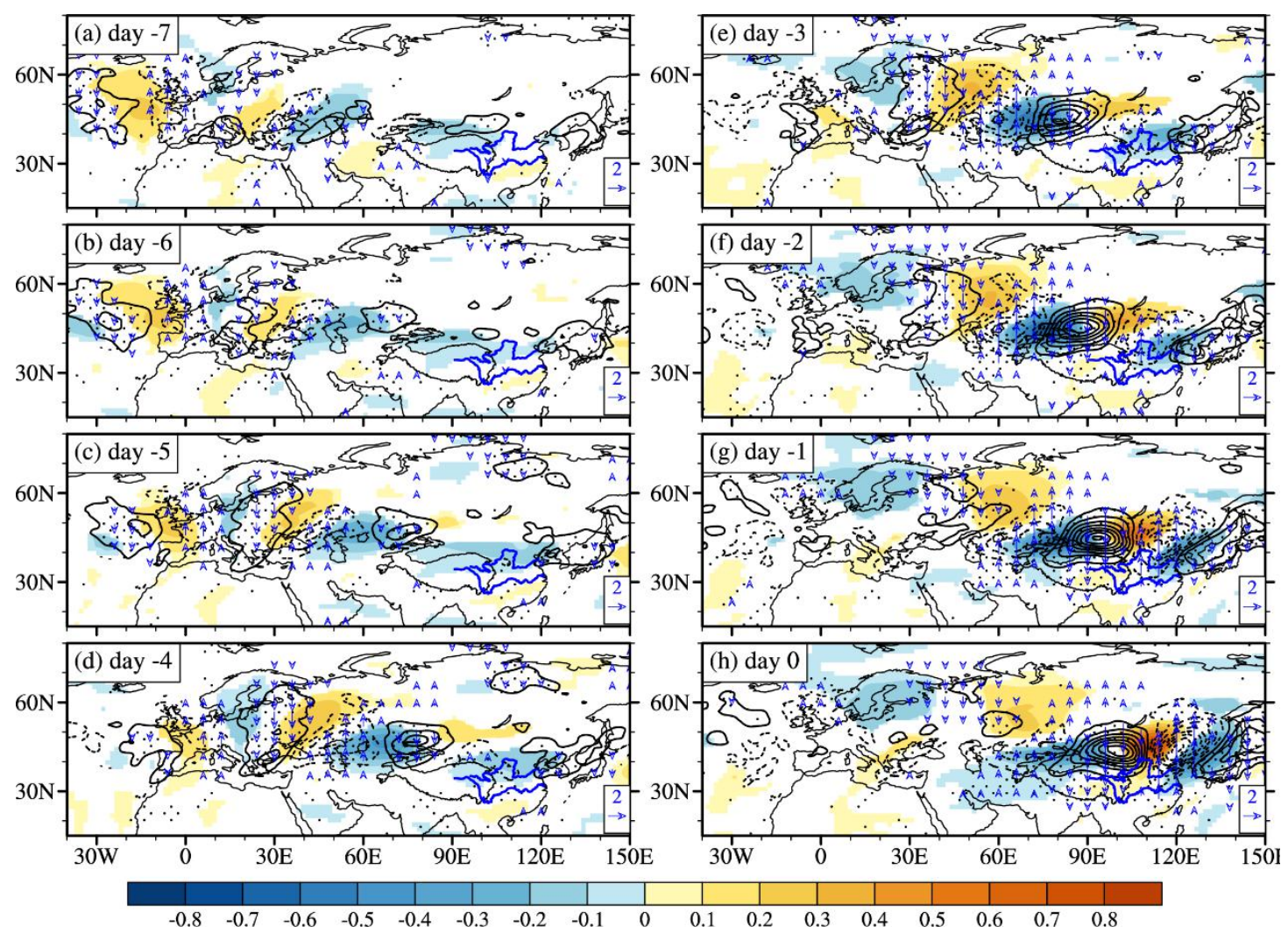

Fig. 7 As in Fig. 6 but for the PV (shaded; units: PVU; statistical significance at 90\% confidence level), meridional PV advection (black contours; units: PVU s ${ }^{-1}$; interval: 0.4 ), and meridional wind anomalies (vector; units: $\mathrm{m} \mathrm{s}^{-1}$; only the vectors that are statistically significant at $95 \%$ confidence level are plotted ) at $200-\mathrm{hPa}$. The stippling areas indicate the $90 \%$ confidence level of the regressed meridional PV advection anomalies. 
(a) $300 \mathrm{hPa}$ tea\&vor_adv anomaly

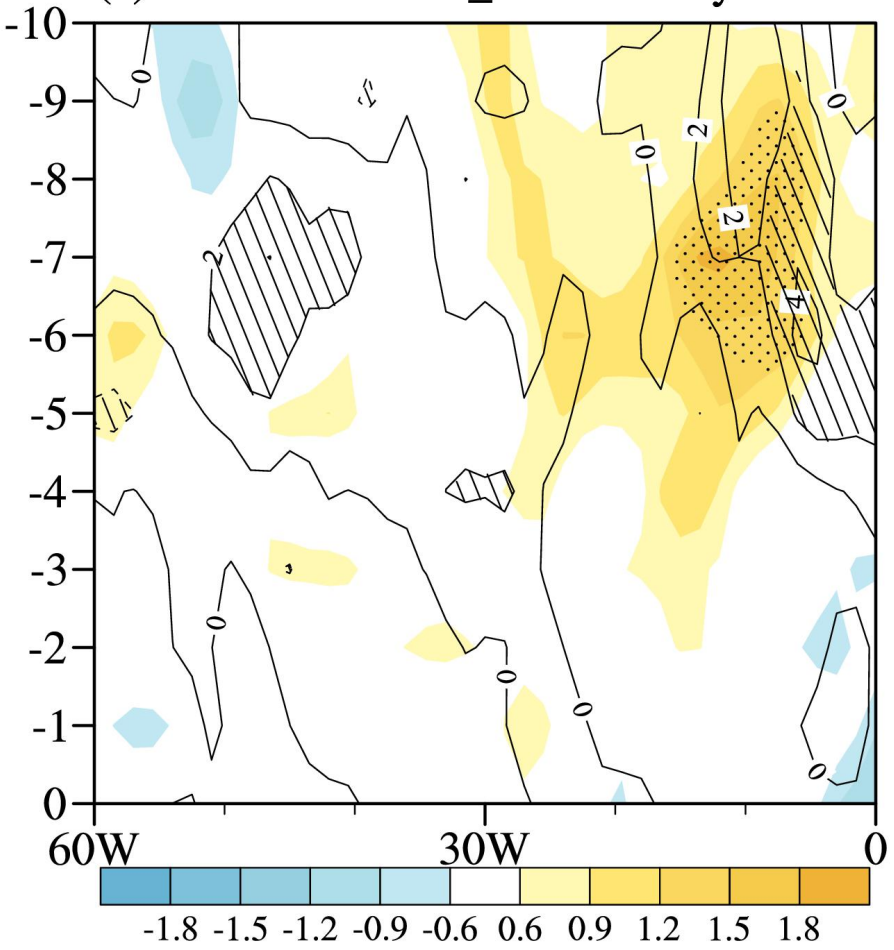

(b) $300 \mathrm{hPa}$ tea\&vor_adv anomaly [day -7 ]

1067

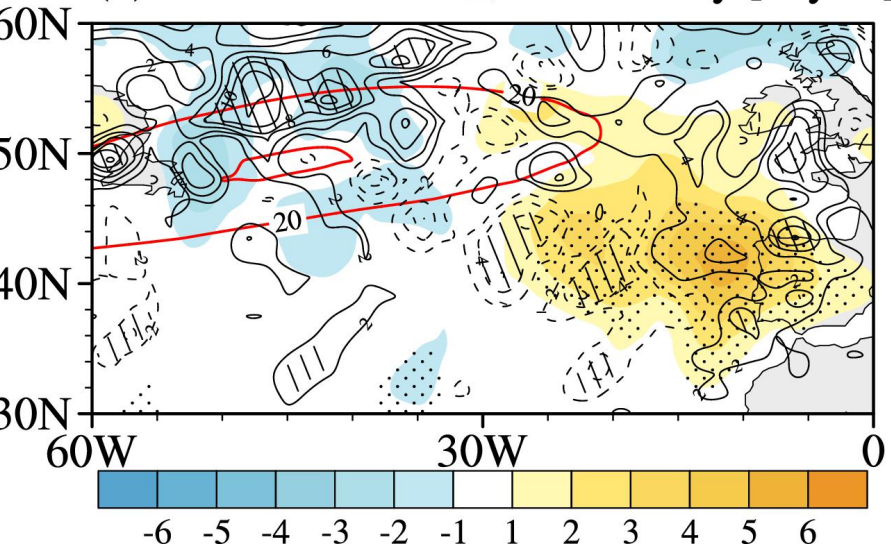

Fig. 8 (a) Temporal evolution of the lead regressions against the PVI from day -10 to day 0 , of transient eddy kinetic energy (shaded; units: $\mathrm{m}^{2} \mathrm{~s}^{-2}$ ) and vorticity advection (contours; units: $10^{-6} \mathrm{~m} \mathrm{~s}^{-2}$; interval 2) anomalies at $300-\mathrm{hPa}$ along the northern North Atlantic $\left(32^{\circ}-58^{\circ} \mathrm{N}\right)$; (b) Geographical distribution of the regressed transient eddy kinetic energy (shaded; units: $\mathrm{m}^{2} \mathrm{~s}^{-2}$ ) and vorticity advection (contours; units: $10^{-6} \mathrm{~m}$ $\mathrm{s}^{-2}$; interval 2 ; value of zero is ignored) anomalies at $300-\mathrm{hPa}$ at day -7 . The red contours denote the westerly jet (units: $\mathrm{m} \mathrm{s}^{-1}$; interval: 4 ; values above 20 are plotted) at 300-hPa. Stipplings and slashes in (a) and b) indicate the $90 \%$ confidence level of the regressions respectively for the transient eddy kinetic energy and vorticity advection anomalies. 
(a) div\&vor\&omega anomaly

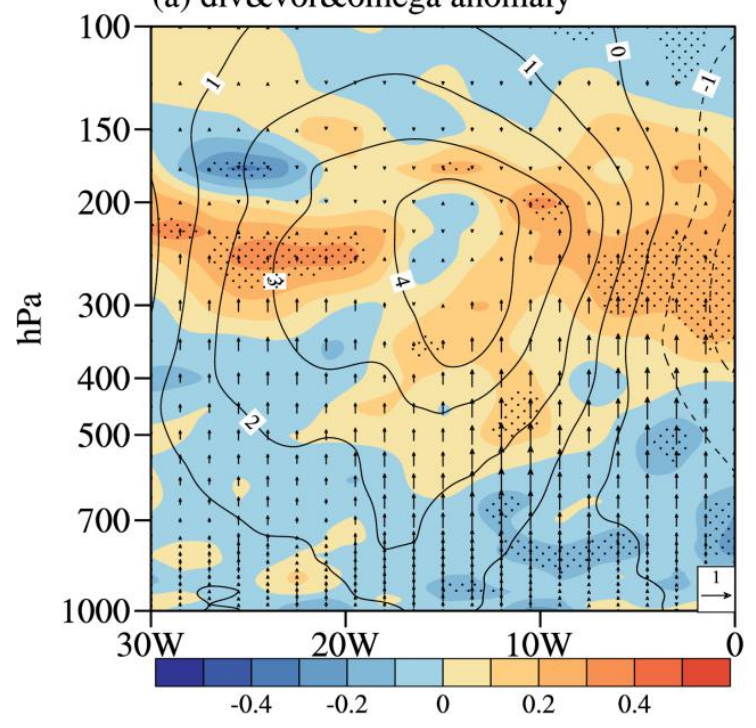

(b) air\&hgt anomaly

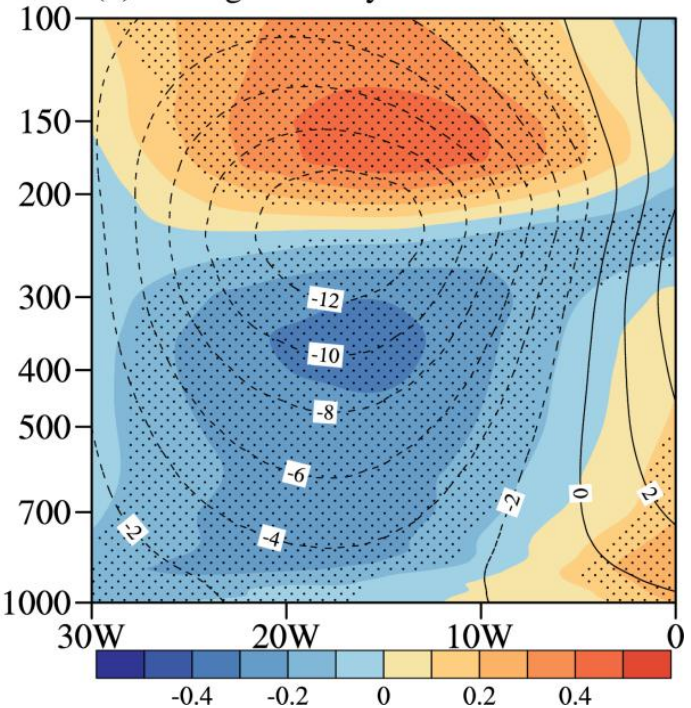

1079

1080

1081

1082

1083

1084

1085

1086

1087

Fig. 9 Vertical cross sections of (a) the regressed horizontal divergence (shaded; units: $10^{-6} \mathrm{~s}^{-1}$ ), relative vorticity (contours; units: $10^{-6} \mathrm{~s}^{-1}$ ), and vertical motion $\omega$ anomalies (vectors; units: $10^{-3} \mathrm{~Pa} \mathrm{~s}^{-1}$ ); and (b) the regressed air temperature (shaded; units: ${ }^{\circ} \mathrm{C}$ ), and geopotential height (contours; units: gpm) anomalies against the PVI along $48^{\circ} \mathrm{N}$ over the northern North Atlantic at day -7 . Stipplings indicate the $90 \%$ confidence level of the regression for (a) the horizontal divergence anomalies and (b) the air temperature anomalies, respectively. The ordinate in $(a, b)$ is the pressure level (units: $\mathrm{hPa})$. 

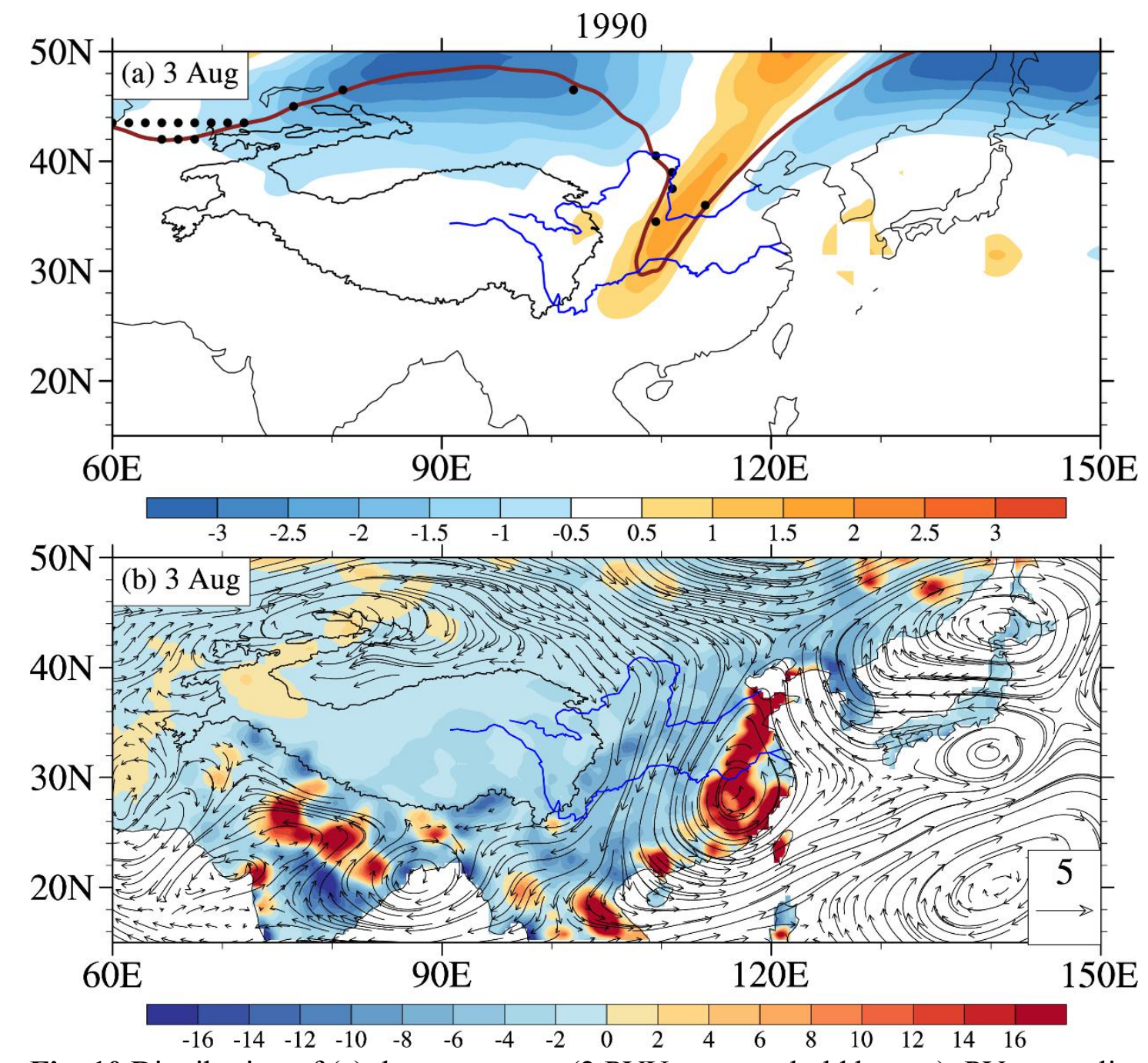

Fig. 10 Distribution of (a) the tropopause (2 PVU contour, bold brown), PV anomalies (shaded; units: PVU) on $350 \mathrm{~K}$ isentropic surface, and (b) horizontal wind anomalies (vector; units: $\mathrm{m} \mathrm{s}^{-1}$ ) at $700-\mathrm{hPa}$ and precipitation anomalies (shaded; units: $\mathrm{mm} \mathrm{d}^{-1}$ ) 1092 on 3 August, 1990. 

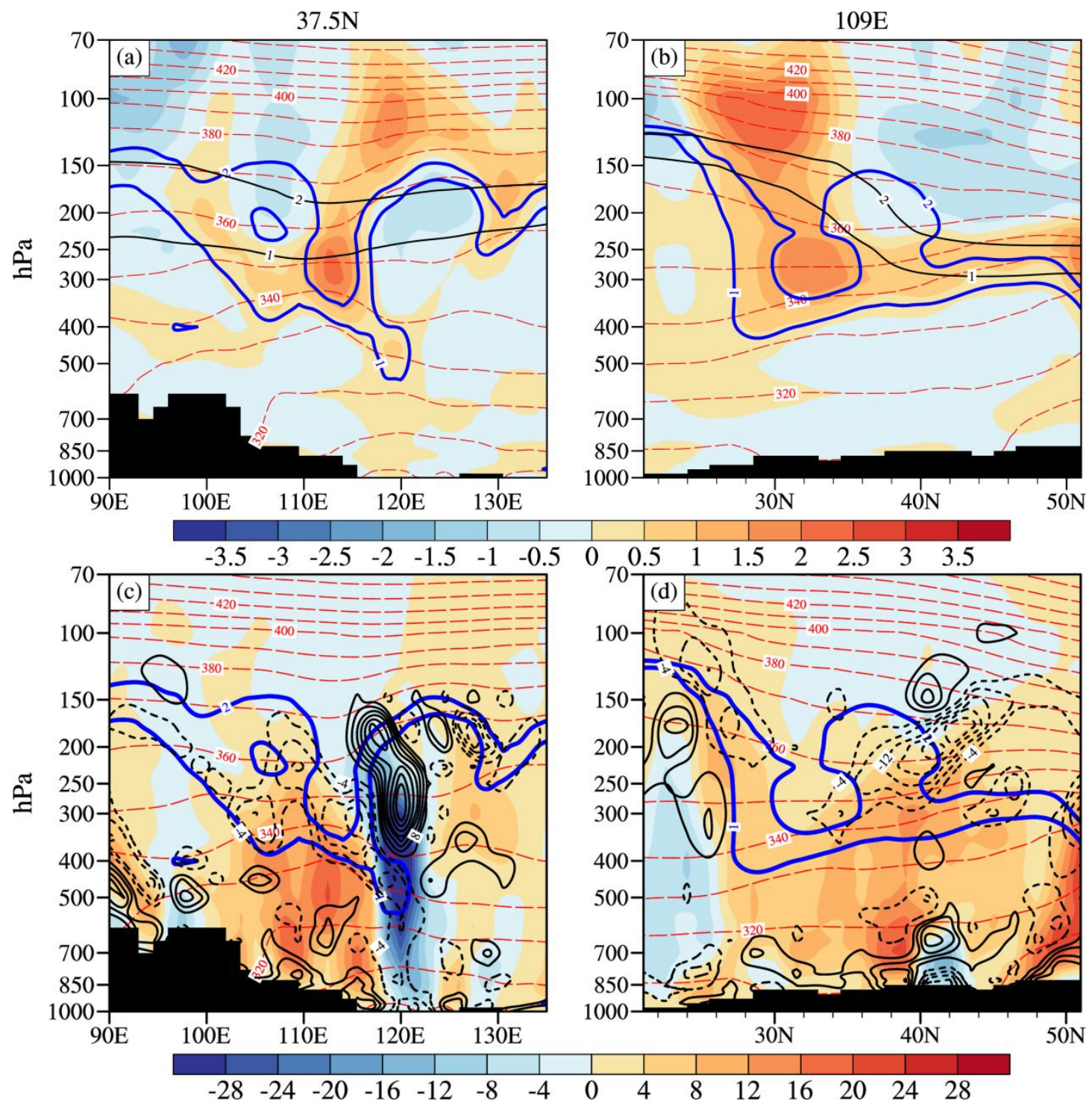

Fig. 11 Vertical cross sections of $(a, b)$ potential temperature (red dashed contours; units: K; interval: 10), PV (blue contours; units: PVU; only values of 1 and 2 PVU are plotted) and its anomalies (shaded; units: PVU) on 3 August, 1990; and (c, d) horizontal divergence anomalies (black contours; units: $10^{-6} \mathrm{~s}^{-1}$; interval: 4; value of zero is neglected), vertical motion $\omega$ (shaded; units: $10^{-2} \mathrm{~Pa} \mathrm{~s}^{-1}$ ) anomalies and PV (blue contours; units: PVU; only values of 1 and 2 PVU are plotted) on 3 August, 1990. The left and right column are for the vertical-longitudinal cross-section along $37.5^{\circ} \mathrm{N}$ and the vertical-latitudinal cross-section along $109^{\circ} \mathrm{E}$ respectively. Black contours in (a,b) are the corresponding summer climatology of 1 and 2 PVU. Areas shaded in black show the topography. 


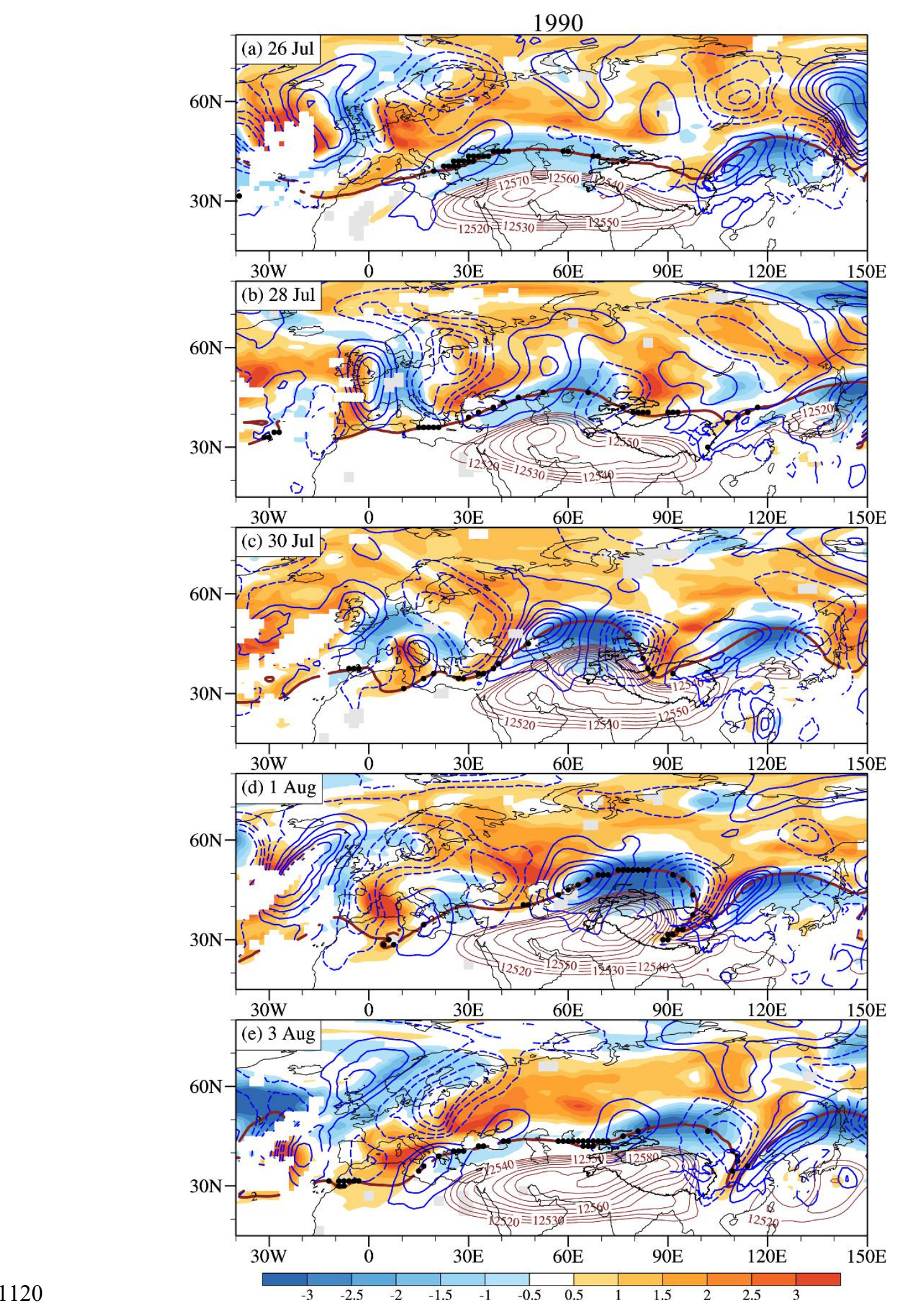

1121 Fig. 12 Distribution of PV (shaded; units: PVU), the tropopause (2 PVU contour, bold 1122 brown) and the meridional wind anomalies (blue contours; units: $\mathrm{m} \mathrm{s}^{-1}$; interval: 6; 1123 value of zero is neglected) at $350 \mathrm{~K}$ isentropic surface, black dots mark the locations 1124 where tropopause folding occurred; And geopotential height at $200 \mathrm{hPa}$ (red contours; 1125 units: gpm; interval: 10; above 12520 gpm) on (a) 26 July, (b) 28 July, (c) 30 July, (d) 11261 August and (e) 3 August, 1990, respectively. 
1990
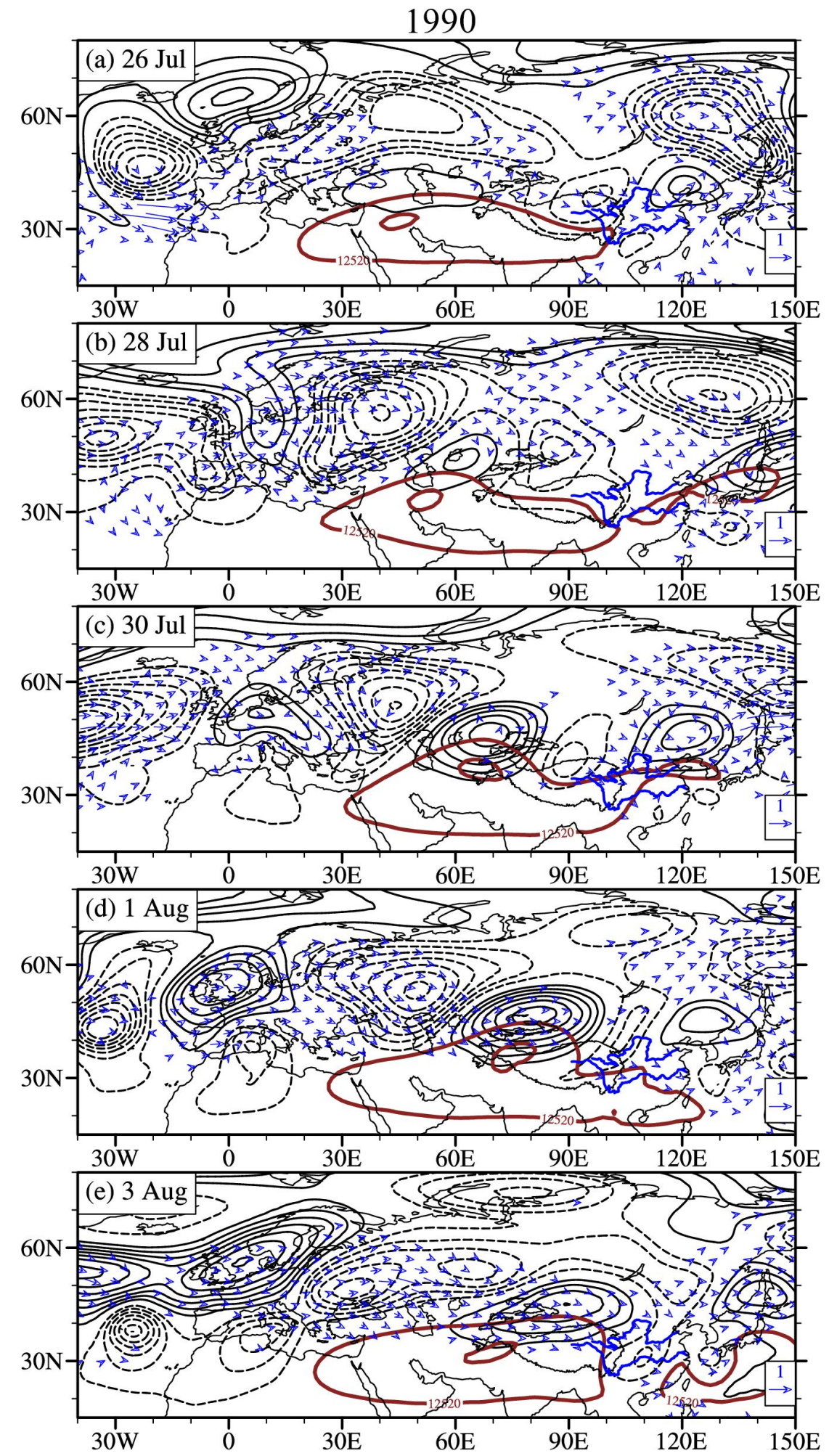

1128 Fig. 13 Spatial distribution of geopotential height (brown contours; units: gpm) and 1129 its anomalies (black contours; units: gpm; interval: 10; value of zero is neglected), and 1130 wave activity flux (vector; units: $10^{2} \mathrm{~m}^{2} \mathrm{~s}^{-2}$; amplitudes larger than 8 are shown) on (a) 113126 July, (b) 28 July, (c) 30 July, (d) 1 August and (e) 3 August, 1990, respectively. 

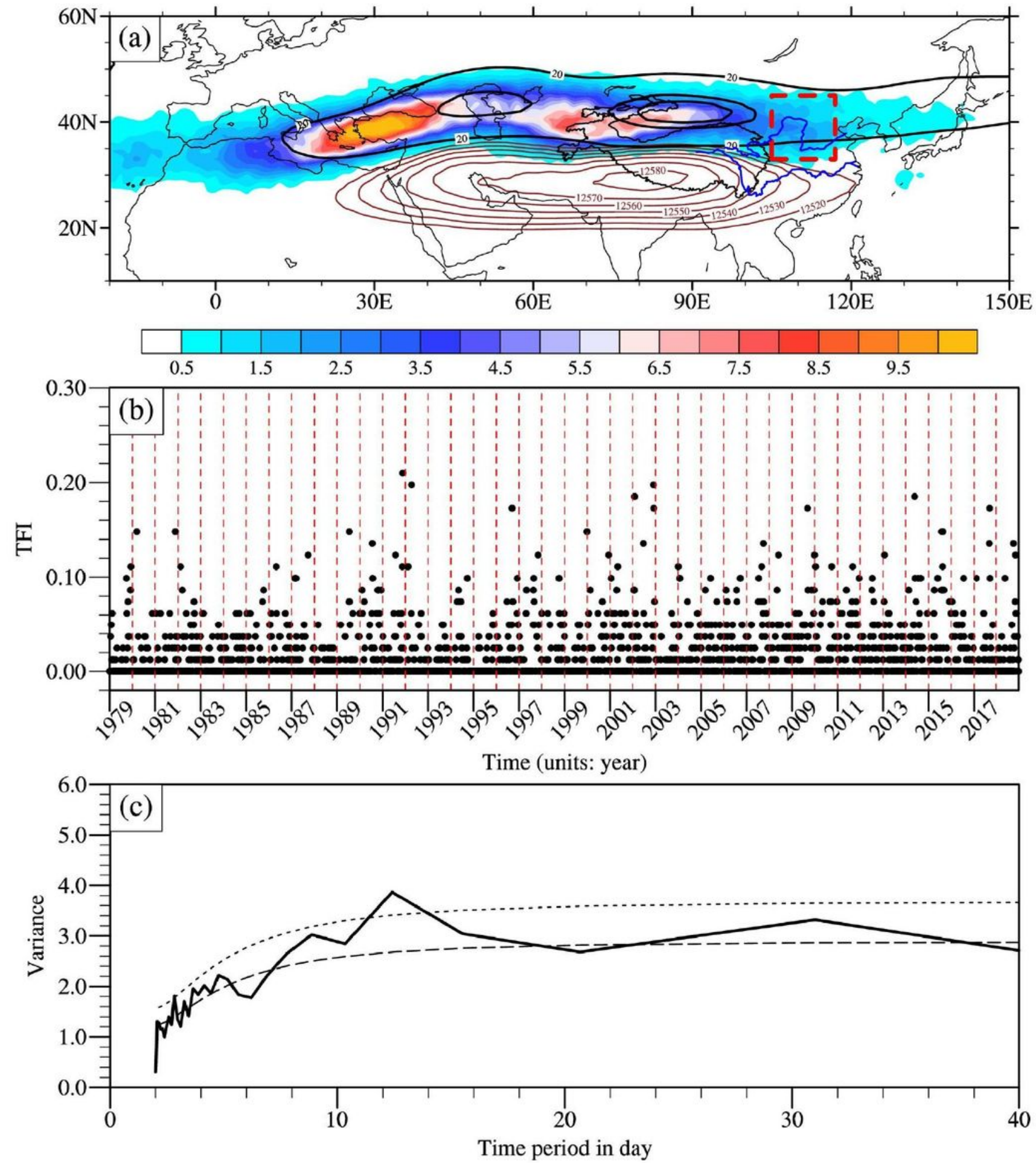

\section{Figure 1}

Please see the Manuscript PDF file for the complete figure caption Note: The designations employed and the presentation of the material on this map do not imply the expression of any opinion whatsoever on the part of Research Square concerning the legal status of any country, territory, city or area or of its 
authorities, or concerning the delimitation of its frontiers or boundaries. This map has been provided by the authors.
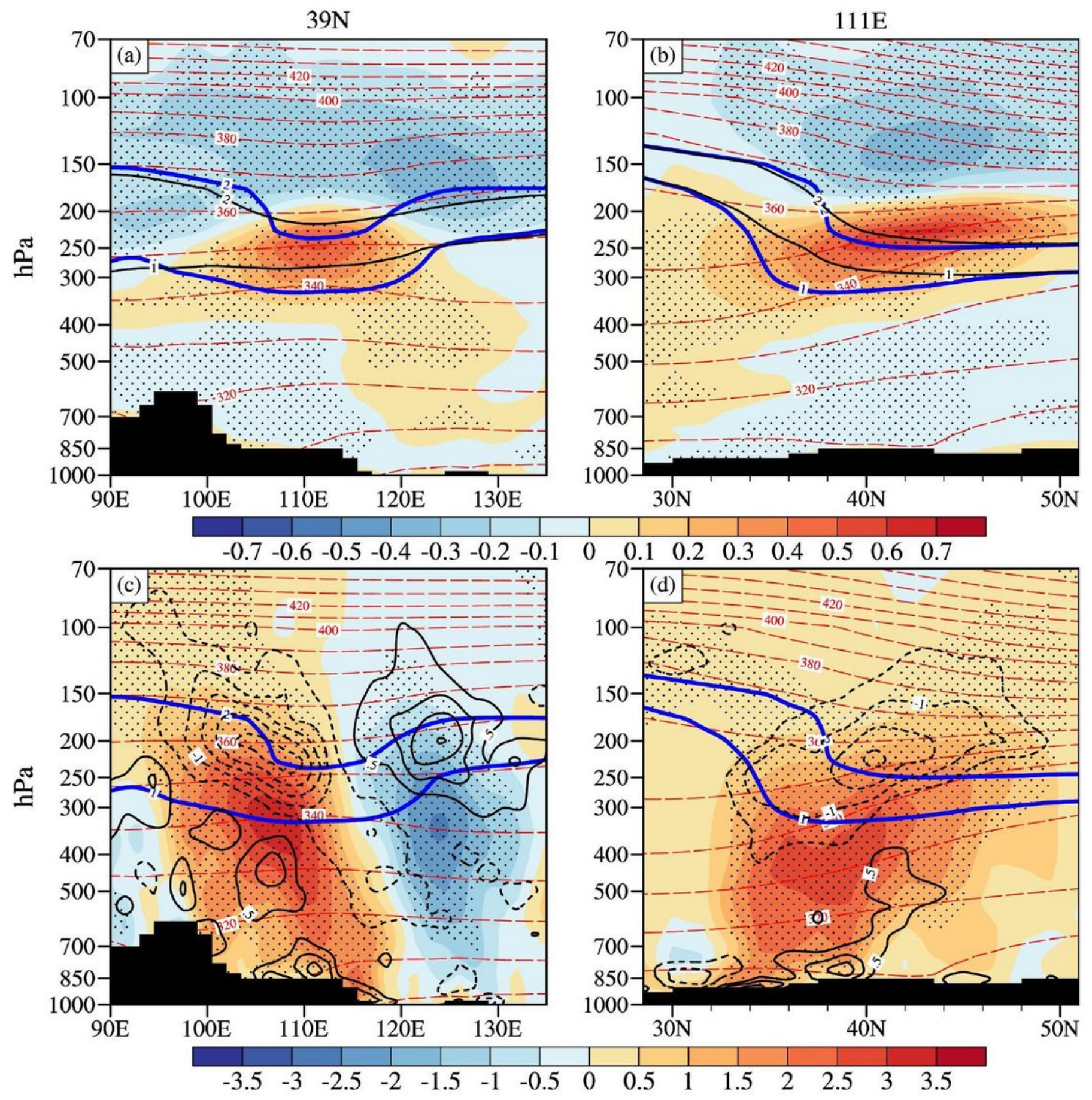

\section{Figure 2}

Please see the Manuscript PDF file for the complete figure caption Note: The designations employed and the presentation of the material on this map do not imply the expression of any opinion whatsoever on the part of Research Square concerning the legal status of any country, territory, city or area or of its authorities, or concerning the delimitation of its frontiers or boundaries. This map has been provided by the authors. 

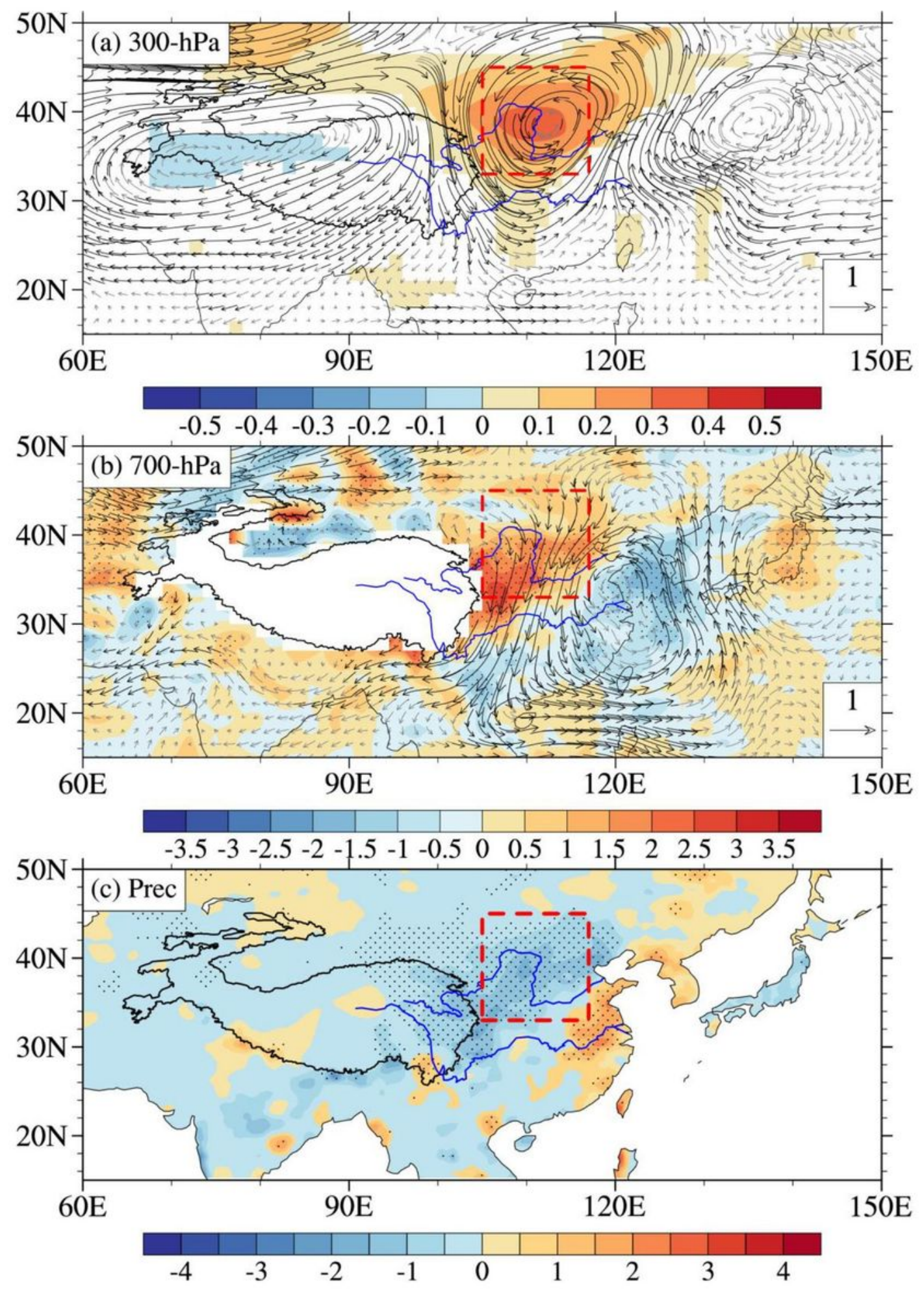

\section{Figure 3}

Please see the Manuscript PDF file for the complete figure caption Note: The designations employed and the presentation of the material on this map do not imply the expression of any opinion whatsoever on the part of Research Square concerning the legal status of any country, territory, city or area or of its authorities, or concerning the delimitation of its frontiers or boundaries. This map has been provided by the authors. 


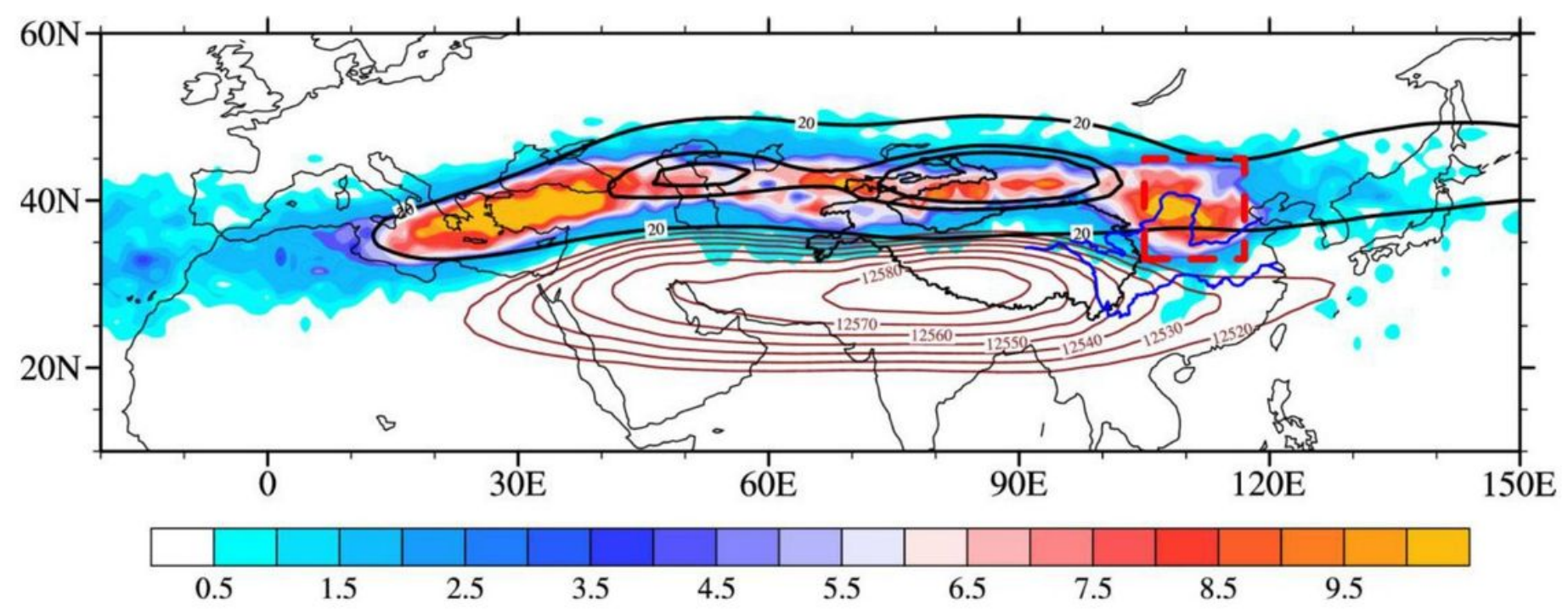

Figure 4

Please see the Manuscript PDF file for the complete figure caption Note: The designations employed and the presentation of the material on this map do not imply the expression of any opinion whatsoever on the part of Research Square concerning the legal status of any country, territory, city or area or of its authorities, or concerning the delimitation of its frontiers or boundaries. This map has been provided by the authors. 

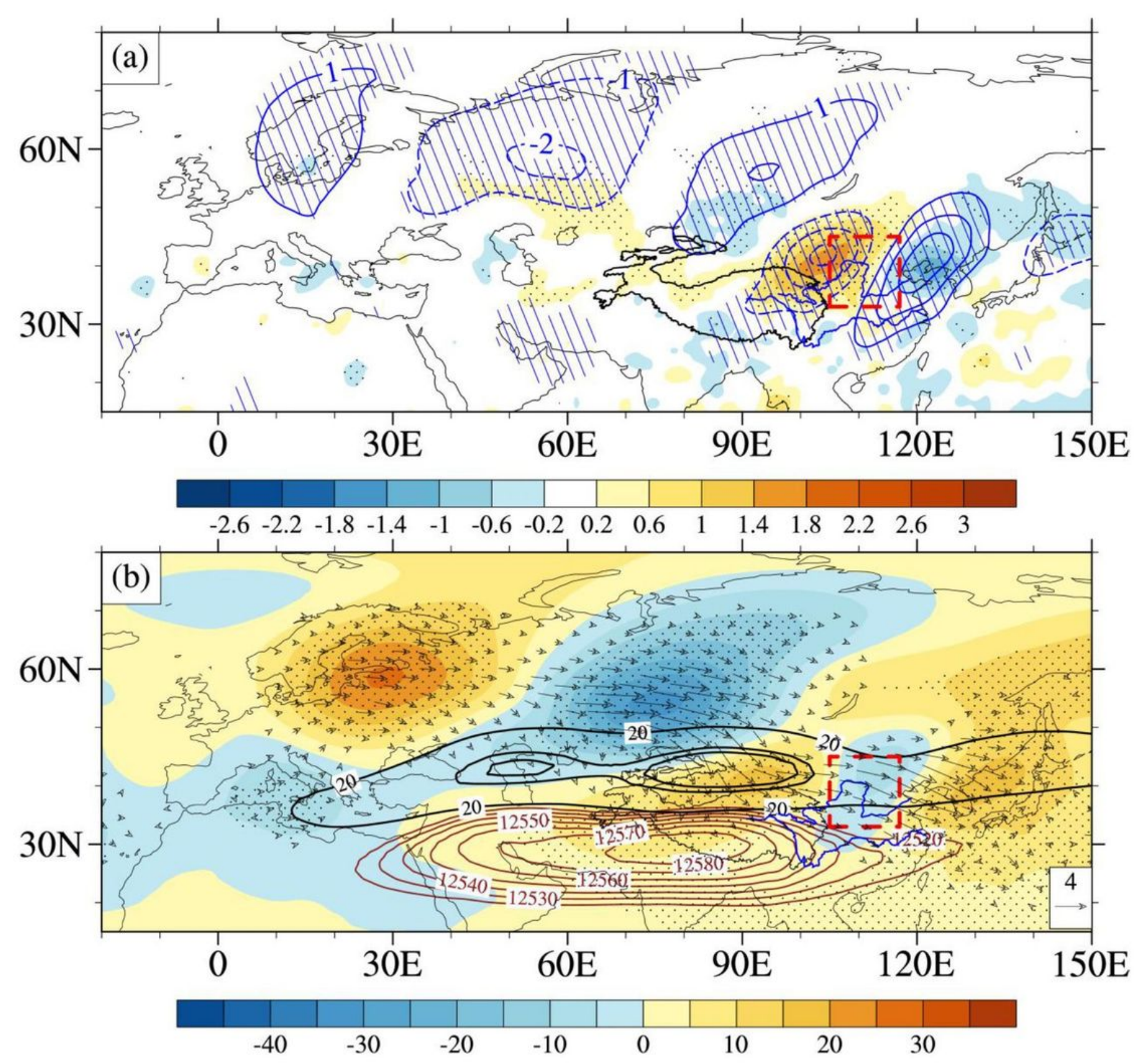

Figure 5

Please see the Manuscript PDF file for the complete figure caption Note: The designations employed and the presentation of the material on this map do not imply the expression of any opinion whatsoever on the part of Research Square concerning the legal status of any country, territory, city or area or of its authorities, or concerning the delimitation of its frontiers or boundaries. This map has been provided by the authors. 

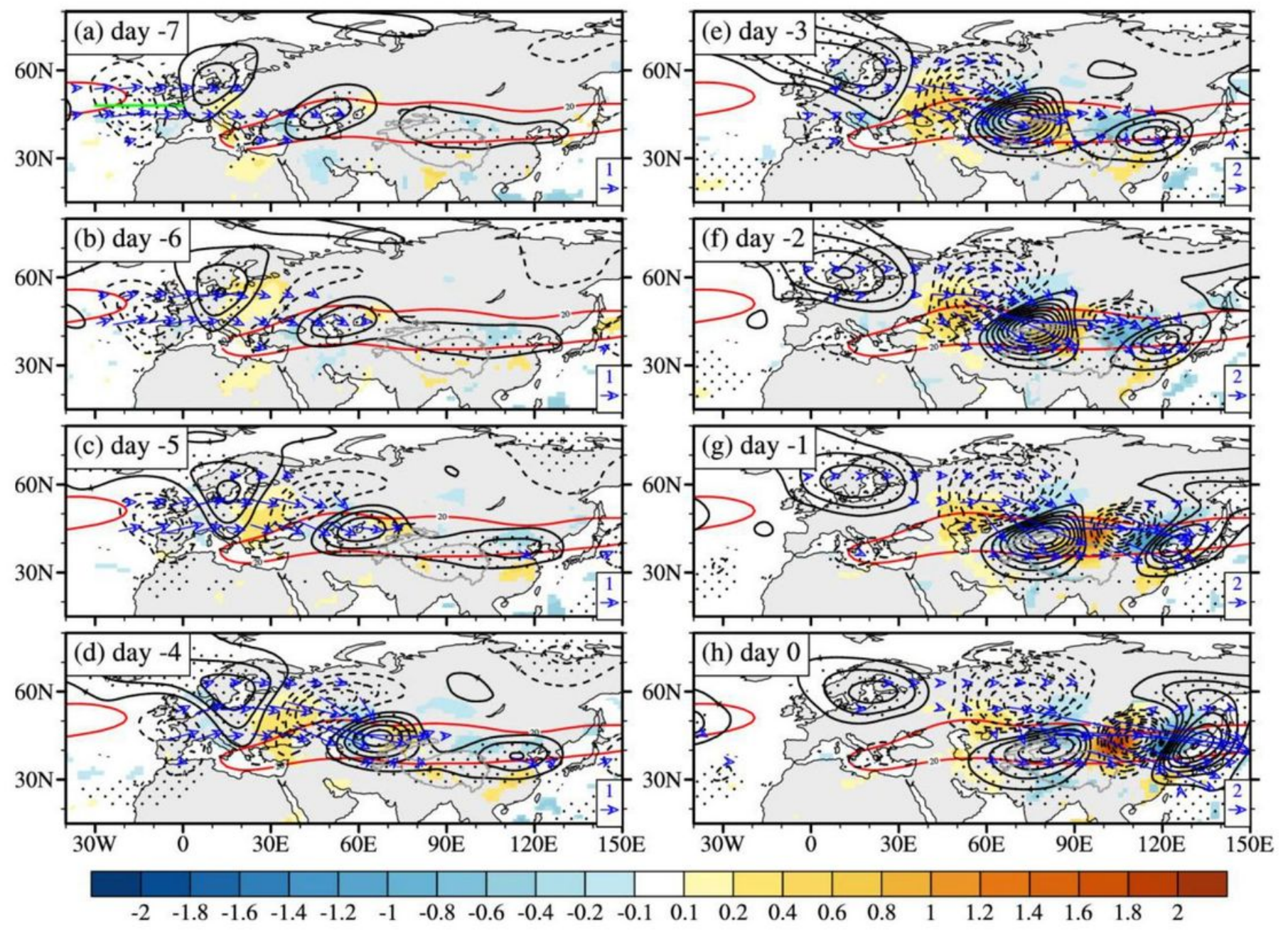

Figure 6

Please see the Manuscript PDF file for the complete figure caption Note: The designations employed and the presentation of the material on this map do not imply the expression of any opinion whatsoever on the part of Research Square concerning the legal status of any country, territory, city or area or of its authorities, or concerning the delimitation of its frontiers or boundaries. This map has been provided by the authors. 

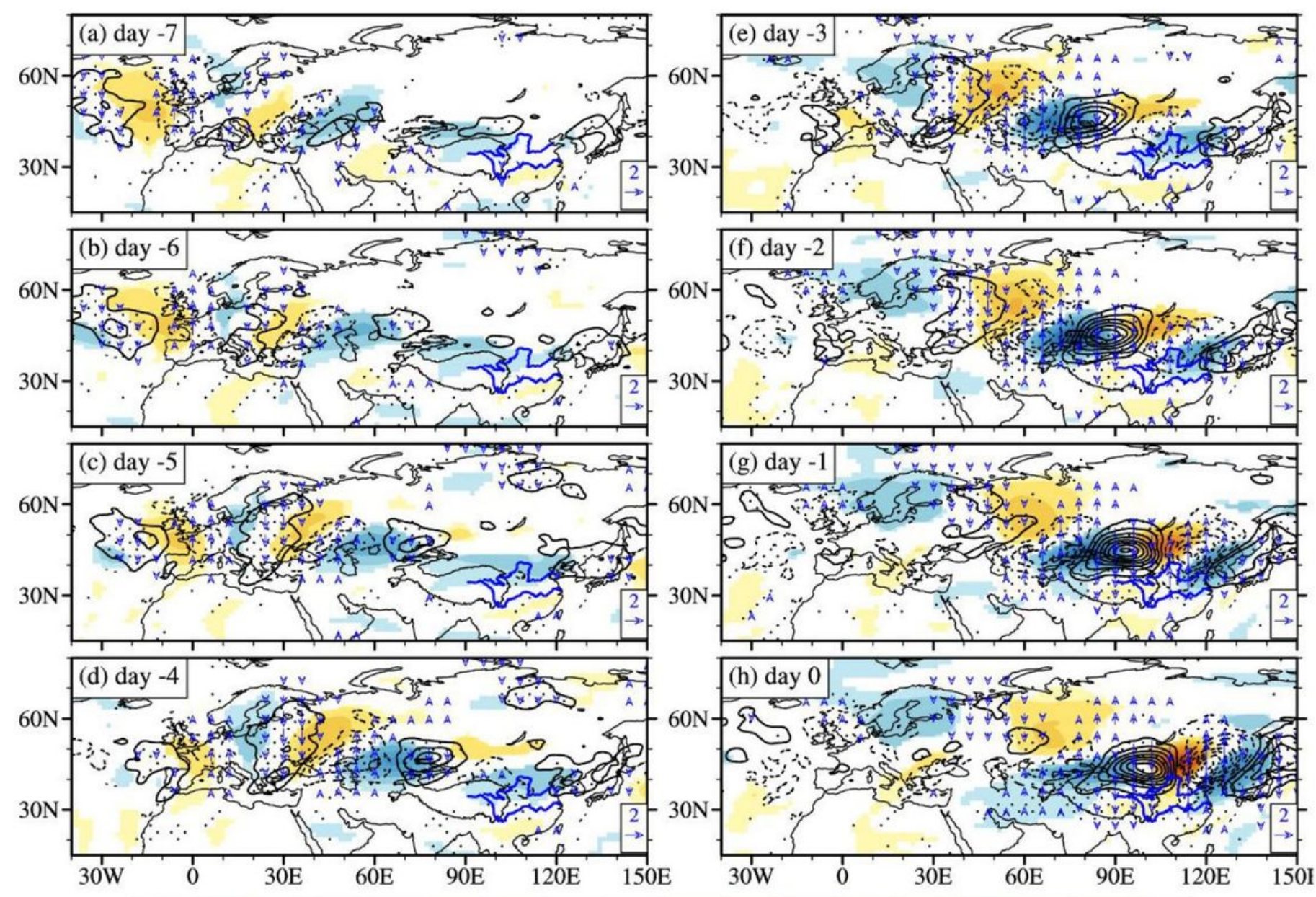

$\begin{array}{lllllllllllllllll}-0.8 & -0.7 & -0.6 & -0.5 & -0.4 & -0.3 & -0.2 & -0.1 & 0 & 0.1 & 0.2 & 0.3 & 0.4 & 0.5 & 0.6 & 0.7 & 0.8\end{array}$

\section{Figure 7}

Please see the Manuscript PDF file for the complete figure caption Note: The designations employed and the presentation of the material on this map do not imply the expression of any opinion whatsoever on the part of Research Square concerning the legal status of any country, territory, city or area or of its authorities, or concerning the delimitation of its frontiers or boundaries. This map has been provided by the authors. 
(a) $300 \mathrm{hPa}$ tea\&vor_adv anomaly

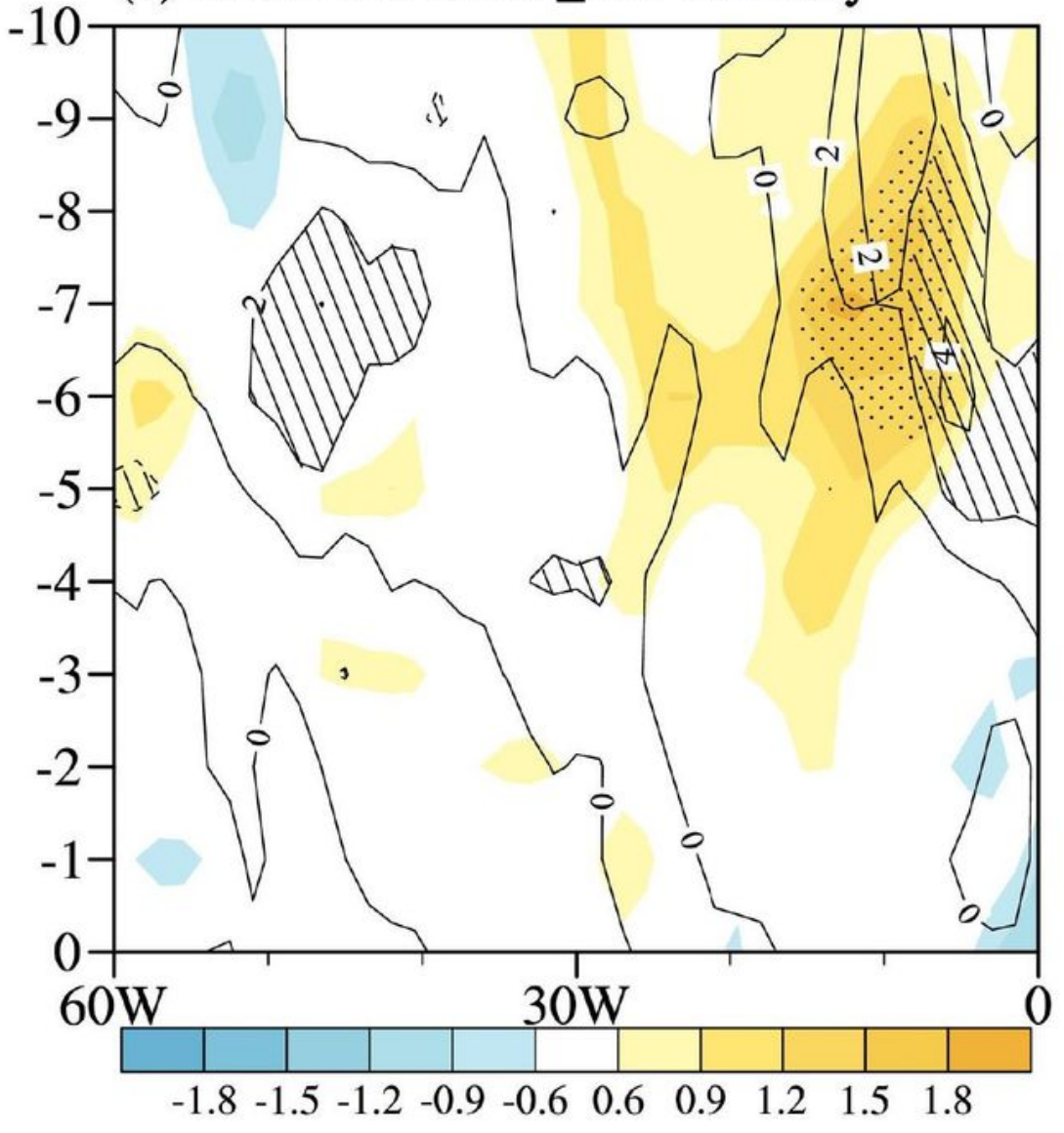

(b) $300 \mathrm{hPa}$ tea\&vor_adv anomaly [day -7]

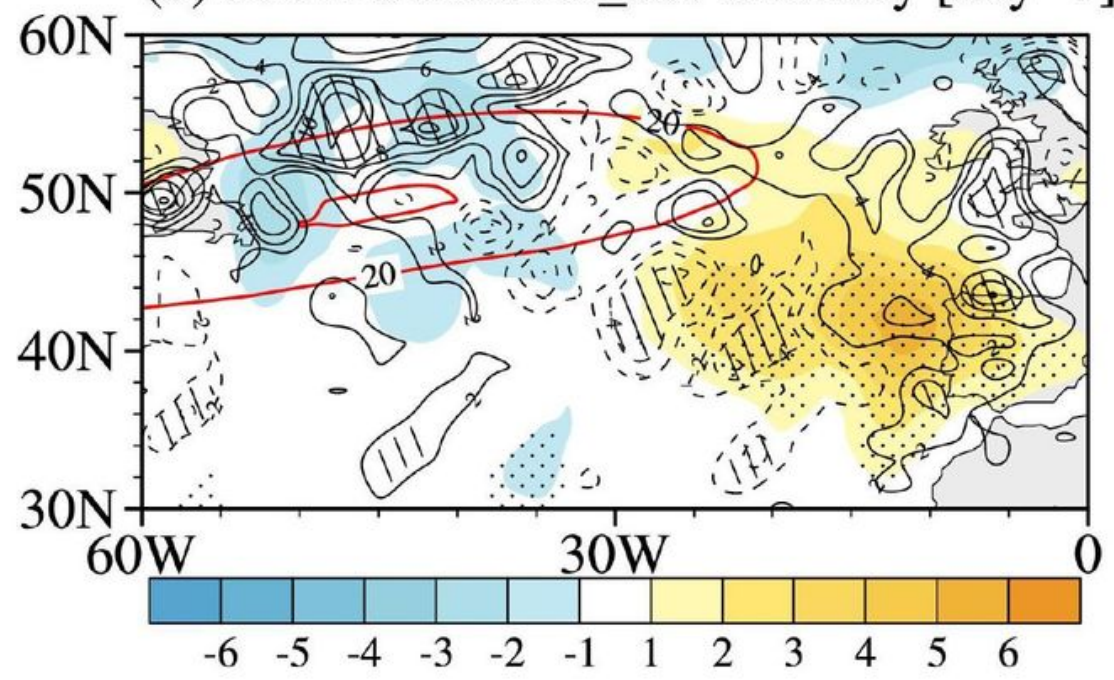

\section{Figure 8}

Please see the Manuscript PDF file for the complete figure caption Note: The designations employed and the presentation of the material on this map do not imply the expression of any opinion whatsoever on the part of Research Square concerning the legal status of any country, territory, city or area or of its authorities, or concerning the delimitation of its frontiers or boundaries. This map has been provided by the authors. 

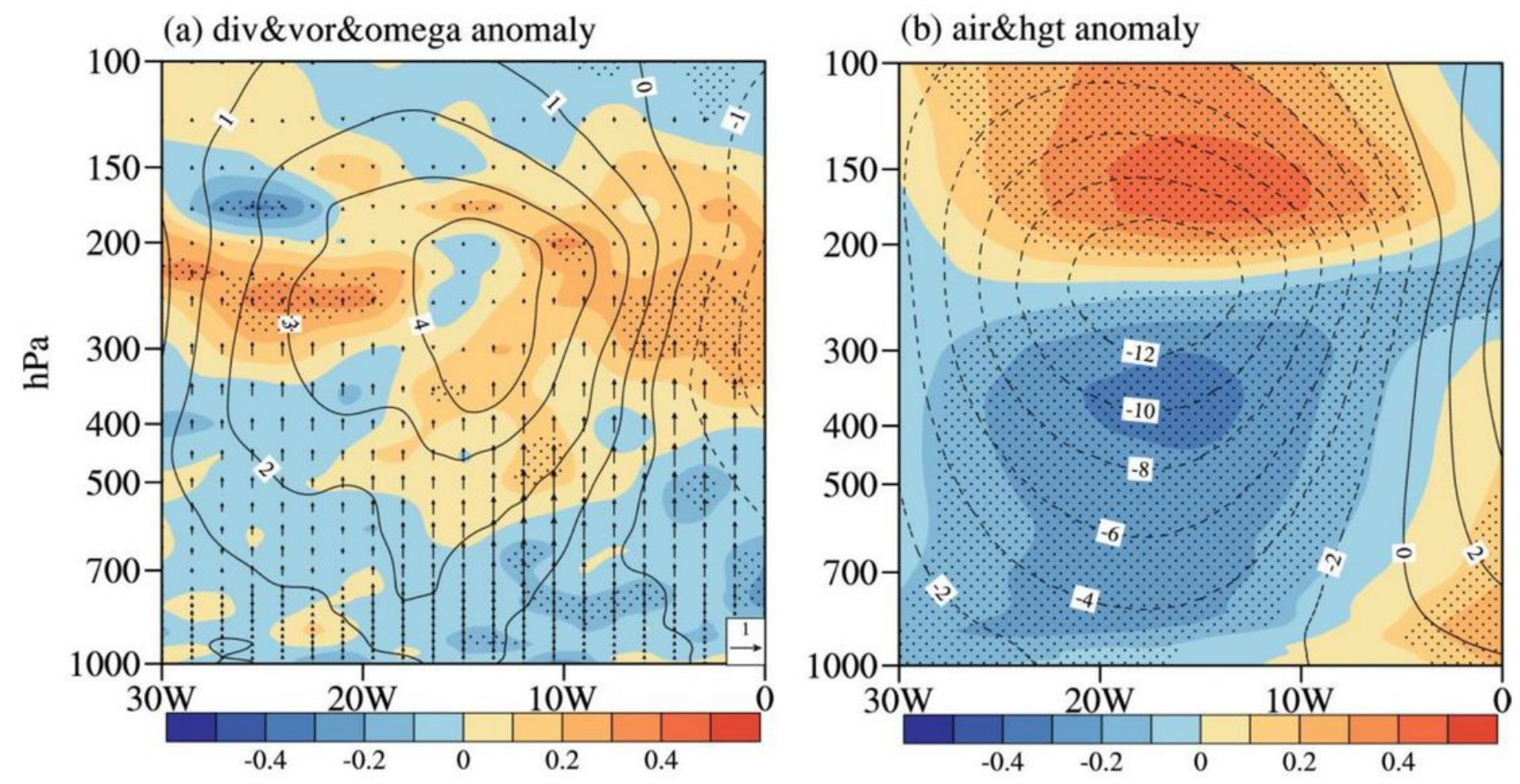

Figure 9

Please see the Manuscript PDF file for the complete figure caption Note: The designations employed and the presentation of the material on this map do not imply the expression of any opinion whatsoever on the part of Research Square concerning the legal status of any country, territory, city or area or of its authorities, or concerning the delimitation of its frontiers or boundaries. This map has been provided by the authors. 


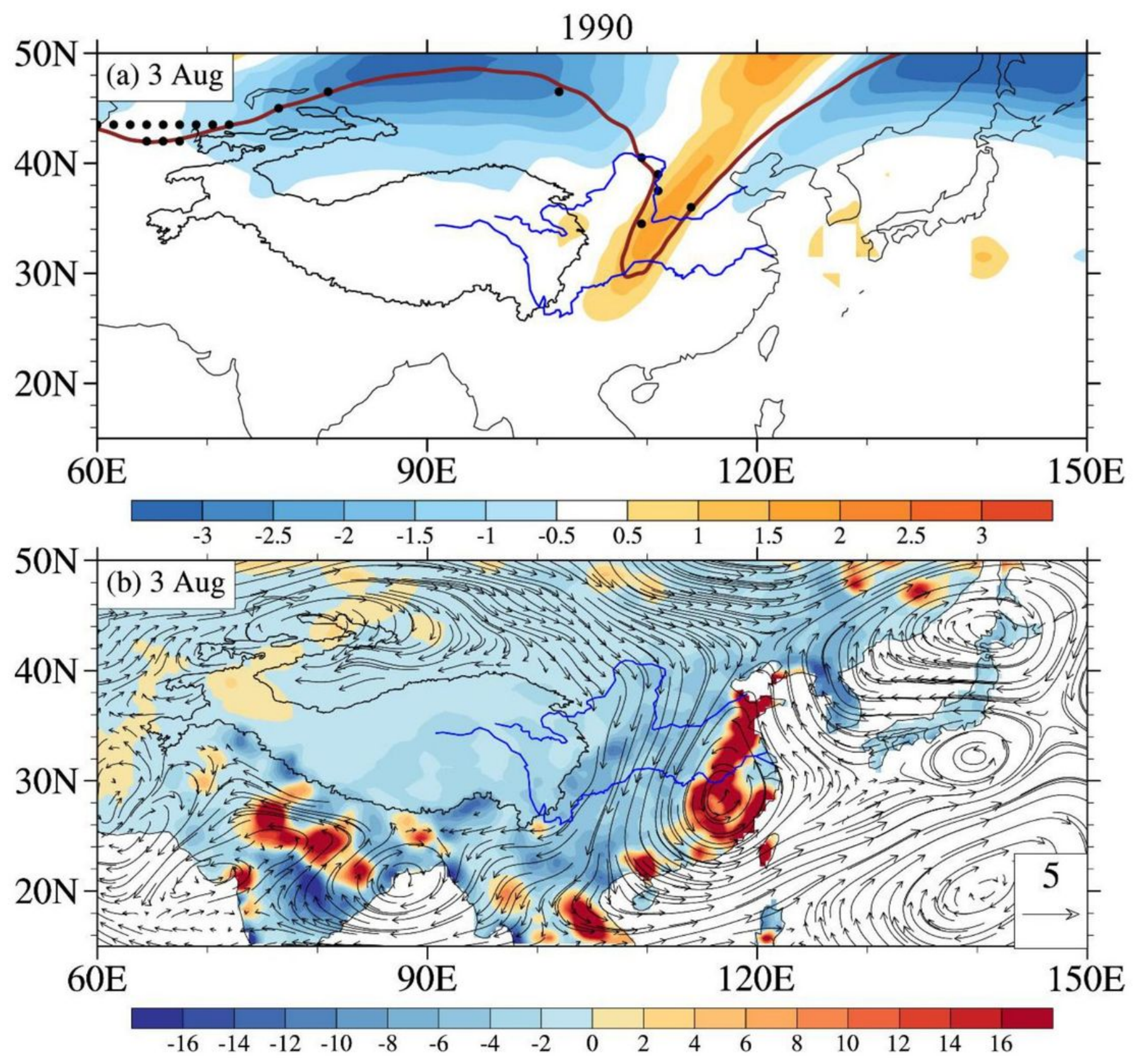

Figure 10

Please see the Manuscript PDF file for the complete figure caption Note: The designations employed and the presentation of the material on this map do not imply the expression of any opinion whatsoever on the part of Research Square concerning the legal status of any country, territory, city or area or of its authorities, or concerning the delimitation of its frontiers or boundaries. This map has been provided by the authors. 

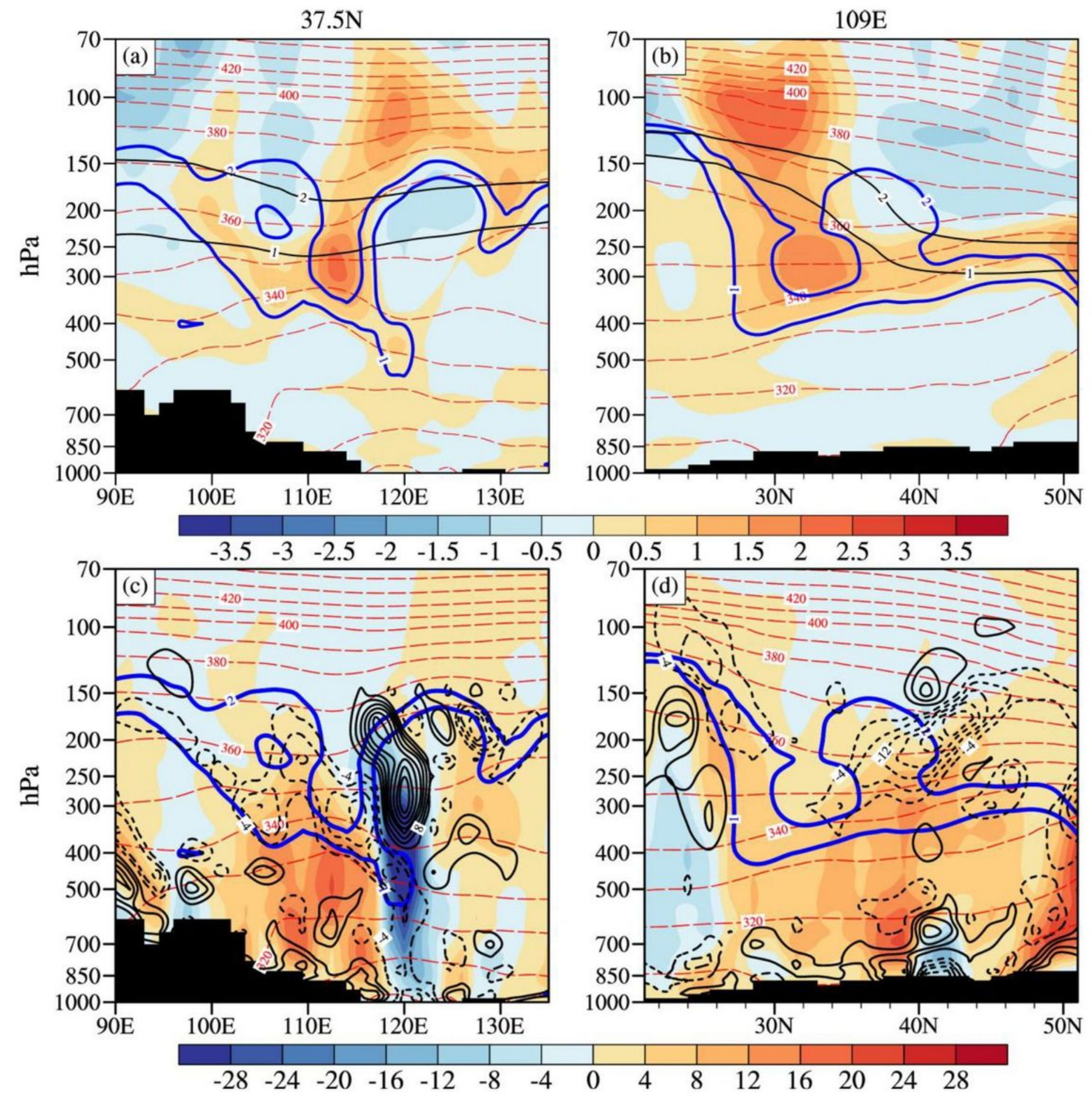

Figure 11

Please see the Manuscript PDF file for the complete figure caption Note: The designations employed and the presentation of the material on this map do not imply the expression of any opinion whatsoever on the part of Research Square concerning the legal status of any country, territory, city or area or of its authorities, or concerning the delimitation of its frontiers or boundaries. This map has been provided by the authors. 

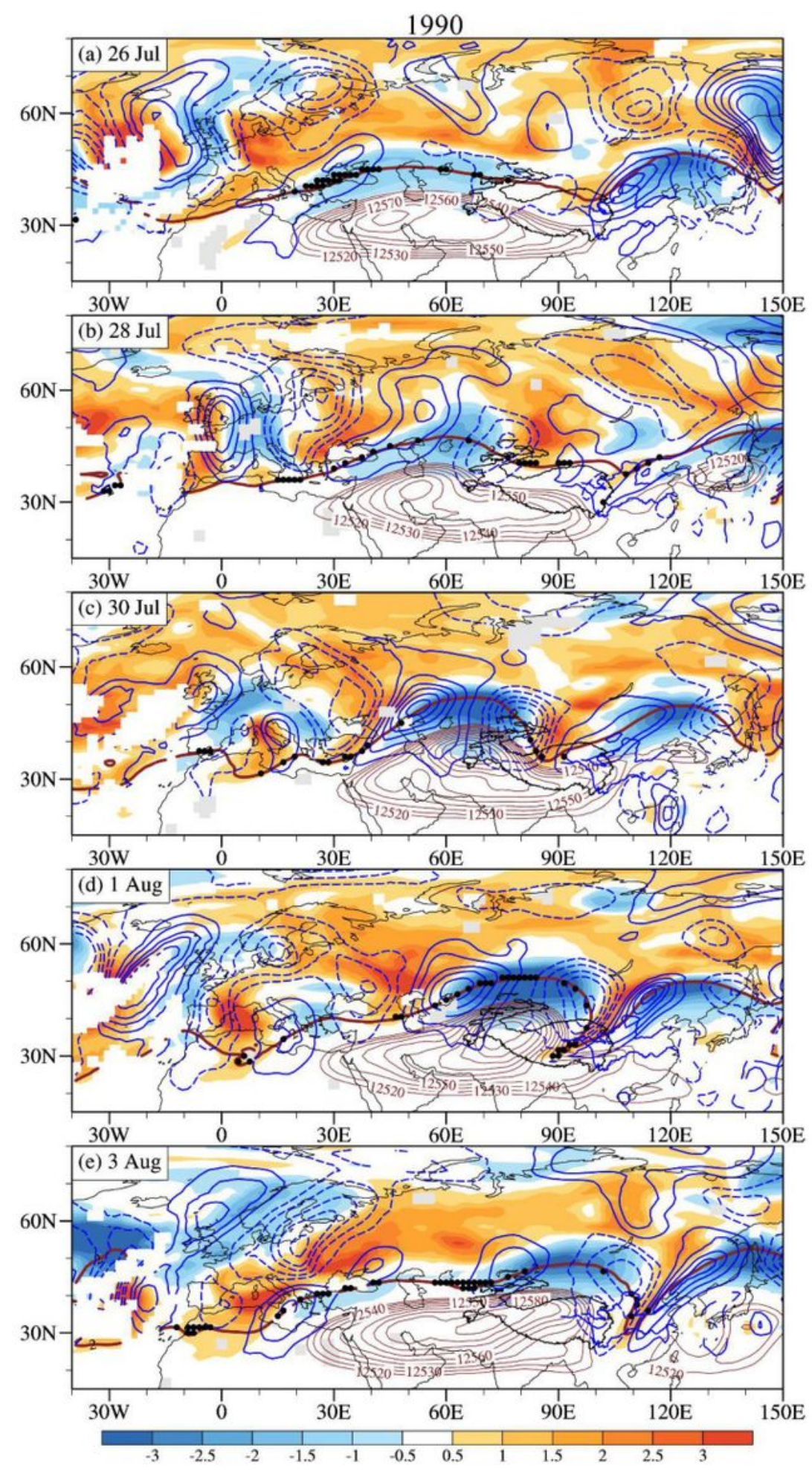

\section{Figure 12}

Please see the Manuscript PDF file for the complete figure caption Note: The designations employed and the presentation of the material on this map do not imply the expression of any opinion whatsoever on the part of Research Square concerning the legal status of any country, territory, city or area or of its authorities, or concerning the delimitation of its frontiers or boundaries. This map has been provided by the authors. 

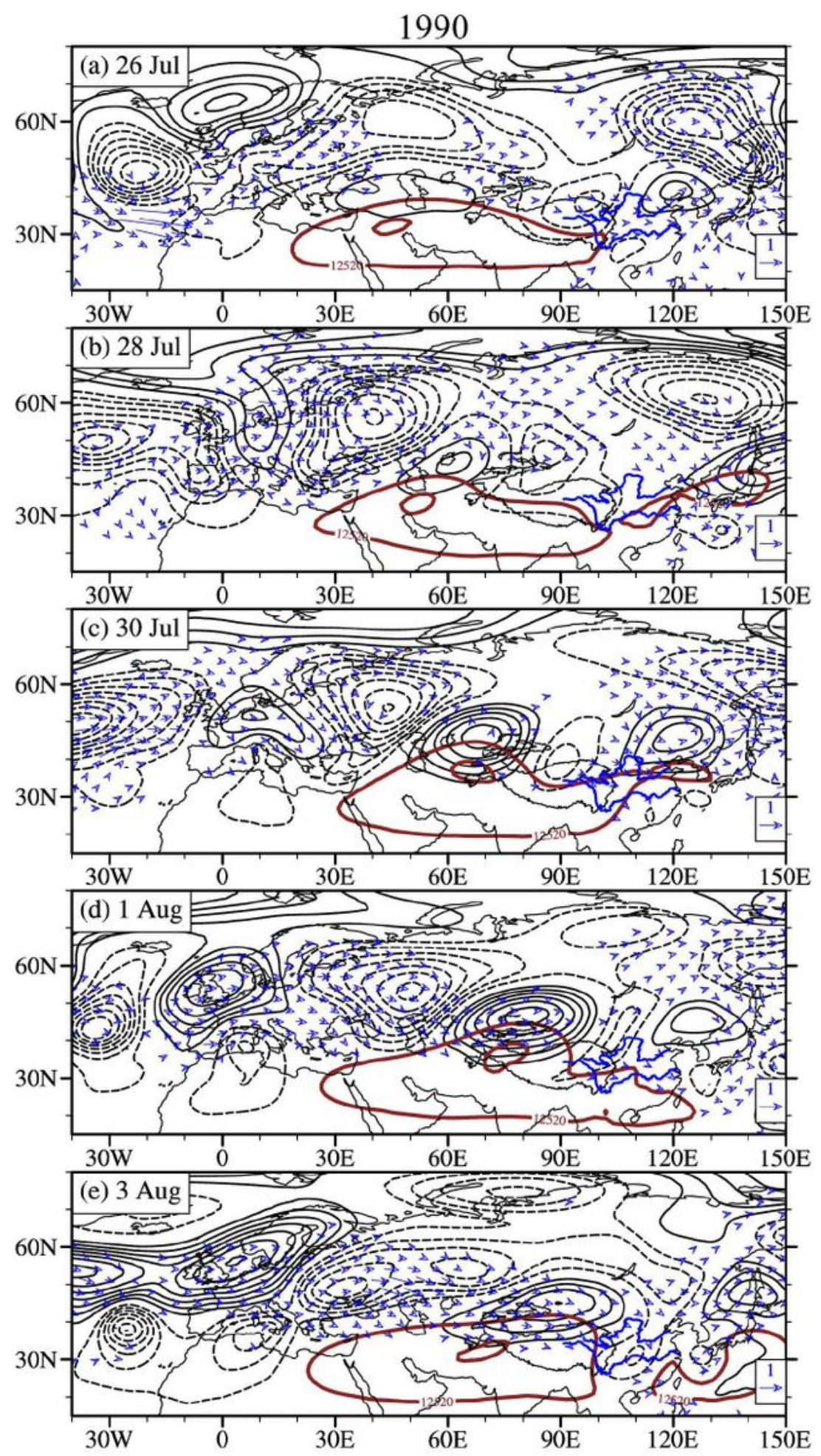

Figure 13

Please see the Manuscript PDF file for the complete figure caption Note: The designations employed and the presentation of the material on this map do not imply the expression of any opinion whatsoever on the part of Research Square concerning the legal status of any country, territory, city or area or of its authorities, or concerning the delimitation of its frontiers or boundaries. This map has been provided by the authors. 